\title{
Night Light-Adaptation Strategies for Photosynthetic Apparatus in Yellow-Poplar (Liriodendron tulipifera L.) Exposed to Artificial Night Lighting
}

\author{
Myeong Ja Kwak ${ }^{1}$, Sun Mi Je ${ }^{1}$, Hyo Cheng Cheng ${ }^{1}$, Se Myeong Seo ${ }^{2}$, Jeong Ho Park ${ }^{1}$, \\ Saeng Geul Baek ${ }^{1}$, Inkyin Khaine ${ }^{1}$, Taeyoon Lee ${ }^{1}$, Jihwi Jang ${ }^{1}$ (D), Yang Li ${ }^{1}$, Haenaem Kim ${ }^{1}$, \\ Jong Kyu Lee ${ }^{1}$, Jieun Kim ${ }^{1}$ and Su Young Woo ${ }^{1, *(D)}$ \\ 1 Department of Environmental Horticulture, University of Seoul, Seoul 02504, Korea; \\ 016na8349@hanmail.net (M.J.K.); jesm0211@korea.kr (S.M.J.); hyocheng80@gmail.com (H.C.C.); \\ parkjeongho82@gmail.com (J.H.P.); bsg1175@naver.com (S.G.B.); inkyinkhainefd@gmail.com (I.K.); \\ taeyoonlee@hotmail.co.kr (T.L.); jangjihwi@naver.com (J.J.); liyyyyang@naver.com (Y.L.); \\ k1h1n1@naver.com (H.K.); gp190@naver.com (J.K.L.); amarg@naver.com (J.K.) \\ 2 Korea Forestry Promotion Institute, Seoul 07570, Korea; ssm9911@kofpi.or.kr \\ * Correspondence: wsy@uos.ac.kr; Tel.: +82-10-3802-5242
}

Received: 30 December 2017; Accepted: 30 January 2018; Published: 2 February 2018

\begin{abstract}
Plants can undergo external fluctuations in the natural light and dark cycle. The photosynthetic apparatus needs to operate in an appropriate manner to fluctuating environmental factors, especially in light. Yellow-poplar seedlings were exposed to nighttime artificial high-pressure sodium (HPS) lighting to evaluate night light-adaptation strategies for photosynthetic apparatus fitness relative to pigment contents, photosystem II photochemistry, photosynthetic parameters, histochemical analysis of reactive oxygen species, and plant biomass. As a result, seedlings exhibited dynamic changes including the enhancement of accessory pigments, the reduction of photosystem II photochemistry, increased stomatal limitation, downregulation of photosynthesis, and the decreased aboveground and belowground biomass under artificial night lighting. Histochemical analysis with $3,3^{\prime}$-diaminobenzidine (DAB) and nitroblue tetrazolium (NBT) staining indicates the accumulation of in situ superoxide radicals $\left(\mathrm{O}_{2}{ }^{-}\right)$and hydrogen peroxide $\left(\mathrm{H}_{2} \mathrm{O}_{2}\right)$ in leaves exposed to the lowest level of artificial night lighting compared to control. Moreover, these leaves exposed to artificial night lighting had a lower nighttime respiration rate. These results indicated that HPS lighting during the night may act as a major factor as repressors of the fitness of photosynthesis and growth patterns, via a modification of the photosynthetic light harvesting apparatus.
\end{abstract}

Keywords: artificial night lighting; chlorophyll $a$ fluorescence transient; photosynthesis related parameters; photosystem II photochemistry; reactive oxygen species

\section{Introduction}

It has been recently reported that light pollution is generated largely by excessive nighttime lighting. Nighttime light pollution generated by excessive external lighting has been demonstrated as an important environmental issue caused by adverse effects such as energy waste [1-5]. Notably, despite the fundamental importance of natural darkness, nighttime artificial lighting has become a globally widespread phenomenon causing light pollution [6].

Light, temperature, water, $\mathrm{CO}_{2}$, and nutrients in forests are also fundamental factors controlling tree growth in forest ecosystems. Especially, light is the main environmental factor that affects plant phenology including seed germination, dormancy breaking, blooming time, defoliation time, etc. $[7,8]$. The naturally fluctuating environments of light and dark are major resources for living organisms. 
The energy trapped by the process of photosynthesis may influence most physiological, behavioral, and ecological patterns of plants. Circadian patterns of light and dark can be linked to patterns of growth and development. The rhythmic availability of light and dark can have negative as well as positive effects on organisms [3].

Plants can experience external fluctuations in the natural light-dark cycle. The photosynthetic apparatus needs to operate in a dynamic manner appropriate to fluctuating environmental factors, especially in light [9]. The rates of plant growth during the night depend on starch degradation rates, whereas leaf maintenance respiration decreases when the rates of starch degradation are down-regulated $[10,11]$. Photosynthesis can be increased by increasing light intensity. However, light-induced production of reactive oxygen species (ROS) occurs by the absorption of excessive light energy, and thus the generation of harmful ROS has the potential for photo-oxidative damage [12,13]. Carbon metabolism can be influenced by circadian or diurnal rhythms. In continuous light, the carbon imbalance caused by the down-regulated photosynthesis [14] leads to accelerated senescence by high accumulation of starch and sugar [15-19].

Lim et al. [19] reported that continuous lighting was sufficient to accelerate leaf senescence by high sugar and photosynthetic downregulation. Accelerated premature senescence results in a major decline of photosynthesis [20] owing to a sequential degradation of chloroplasts, including Ribulose-1,5-bisphosphate carboxylase/oxygenase (Rubisco) and chlorophyll degradation. In chloroplast thylakoids, the reaction centers of photosystem I (PSI) and photosystem II (PSII) are the major sites of reactive oxygen species generation, since they possess a source-rich environment such as oxygen, reducing agents, and high-energy components [21,22]. In addition, the highly reduced state of photosynthetic electron carriers enhances the reduction of $\mathrm{O}_{2}$ by PSI, resulting in the subsequent formation of ROS $[23,24]$. Previous studies have also focused on the benefits of plant growth and development on continuous light as supplemental lighting relative to the existing light quality and lighting period [14,15,18]. More recently, Tewolde et al. [25] documented that nighttime lighting can stimulate physiological functions such as photosynthesis and yield and can lead to a significant improvement in biochemical function. On the other hand, some studies have shown that plants have adaptive strategies regulating many processes such as increasing the mesophyll tissue thickness and relocating chloroplasts to minimize damage under high light $[26,27]$.

Since the early 1900s, artificial street lighting has been used to provide a safe and comfortable environment for every aspect of life, including residence, business, trade, traffic, and commerce. However, ongoing advances in street lighting technology have led to the increasing adoption of broader spectrum light sources such as high-pressure sodium (HPS) [28]. While incidental exposure to artificial lighting at night can indirectly affect many organisms by drastically altering the natural day/night cycle in their environments [1], organisms, including plants, must adapt to temporal and spatial features of their surroundings to successfully survive and reproduce. Importantly, photosynthetic organisms have specific wavelength absorption patterns across the absorption spectrum [29]. Primary light harvesting chlorophyll absorbs light in the blue (400-500 nm) and red (600-700 nm) regions, while accessory light-harvesting carotenoids absorb light in the blue and green portions (450-550 nm) of the spectral range.

Light pollution caused by artificial night lighting has been recognized as both a global environmental issue and an important ecological problem in urbanized habitats, and not as supplementary light for productivity as was intended, and the ecological effect has only begun to be examined in detail. Our previous study has shown that stomata exposed to artificial night lighting (1) fail to exhibit normal movement by malfunctioning abscisic acid (ABA)-mediated signaling due to photoperiod shifts, and (2) thus experience incomplete starch synthesis and degradation, resulting in carbon starvation stress [30]. Despite light pollution being recognized as an important ecological risk factor for wildlife, artificial night lighting, as a source of light pollution, can be suggested as a source of physio-biochemical oscillating disorders in plants in urban environments surrounded by HPS lamps emitting a broad spectrum. 
Current knowledge of effects of artificial night lighting in urbanized habitats is insufficient to determine whether it causes any major problems in plants. Meanwhile, it is still largely unknown whether there are important effects on physio-biochemical responses of plants under nighttime artificial lighting. Based on the above questions, the present study tested the following core hypotheses of artificial night lighting in physio-biochemical attributes: artificial night lighting (1) plays a modifying role in photoperiod perception, (2) leads to the inhibition of photosystem II electron transport, and therefore (3) results in a modification of the photosynthetic light harvesting apparatus.

\section{Materials and Methods}

\subsection{Plant Materials and Growth Conditions}

This experiment was performed to investigate the effects of artificial night lighting on photosynthetic activity and growth responses in yellow-poplar (Liriodendron tulipifera L.). Yellow-poplar is a street tree species that is planted in urban areas, and is commonly known as a wide-spread, fast-growing pioneering hardwood species of considerable economic value. One-year-old seedlings obtained from the Korea Forest Service were transplanted into $3 \mathrm{~L}$ plastic pots containing artificial soil of cocopeat, peatmoss, perlite, and vermiculite. These seedlings were grown in a greenhouse under ambient conditions at the University of Seoul from April 2012 until August 2015 and exposed to four lighting regimes, which corresponded to $\mathrm{C} 0, \mathrm{~T} 1, \mathrm{~T} 2$, and $\mathrm{T} 3$ manipulated as 0 , 1,3 , and $50 \mu \mathrm{mol} \cdot \mathrm{m}^{-2} \cdot \mathrm{s}^{-1}$, respectively. C0 seedlings were assigned to natural sunlight/night cycle as a control. T1, T2, and T3 seedlings were exposed to a photoperiod of $13 \mathrm{~h}: 11 \mathrm{~h}$ (a natural sunlight/artificial night lighting cycle) using an HPS lamp. After exposure to artificial night lighting, leaves were analyzed for photosynthetic pigments, chlorophyll fluorescence parameters, photosynthetic gas exchange, oxidative stress and enzyme activity, lipid peroxidation and membrane permeability, and plant biomass during the growing season between 2013 and 2015. The natural sunlight/artificial night lighting cycle was applied using an HPS lamp representative of the most common type of street lighting with broad spectrum. The natural day/night cycle growing area was surrounded with black curtains to block artificial lighting during the night.

\subsection{Quantification of Photosynthetic Pigments}

Leaf samples were put into plastic bags, placed in an icebox, and transported immediately to the laboratory. The fresh leaves were chopped into small pieces using a cork borer for the quantitative determination of major (chlorophyll) and accessory (carotenoids) photosynthetic pigments. Chopped leaf samples $(0.1 \mathrm{~g})$ were placed into vials in quintuplicates containing $10 \mathrm{~mL}$ of $80 \%(\mathrm{w} / \mathrm{v})$ acetone per vial. The vials were then stored in a refrigerator at $4{ }^{\circ} \mathrm{C}$ for 7 days to ensure a complete leaching of the pigments. Thereafter, photosynthetic pigments (chlorophyll $a, \mathrm{Chl}_{\mathrm{a}}$; chlorophyll $b$, $\mathrm{Ch}_{\mathrm{b}}$ ), total pigment contents (total chlorophyll, $\mathrm{Chl}_{\mathrm{T}}$; total carotenoid, $\mathrm{Car}_{\mathrm{T}}$ ), pigment ratio (ratio of $\mathrm{Chl}_{\mathrm{a}}$ to $\mathrm{Chl}_{\mathrm{b}}, \mathrm{Chl}_{\mathrm{a}} / \mathrm{Chl}_{\mathrm{b}}$; ratio of $\mathrm{Car}_{\mathrm{T}}$ to $\mathrm{Chl}_{\mathrm{T}}, \mathrm{Car}_{\mathrm{T}} / \mathrm{Chl}_{\mathrm{T}}$ ), and ratio of chlorophyll $a$ or $b$ to total chlorophyll (ratio of $\mathrm{Chl}_{\mathrm{a}}$ to $\mathrm{Chl}_{\mathrm{T}}, \mathrm{Chl}_{\mathrm{a}} / \mathrm{Chl}_{\mathrm{T}}$; ratio of $\mathrm{Chl}_{\mathrm{b}}$ to $\mathrm{Chl}_{\mathrm{T}}, \mathrm{Chl}_{\mathrm{b}} / \mathrm{Chl}_{\mathrm{T}}$ ) were determined according to the method by Arnon [31]. Absorbance values for the supernatants were recorded at the wavelength of $663 \mathrm{~nm}, 645 \mathrm{~nm}$ and $470 \mathrm{~nm}$ using a UV-Vis spectrophotometer (Optizen 2120 UV, Mecasys, Daejeon, Korea) against $80 \%$ acetone as a blank. The $\mathrm{Chl}_{\mathrm{a}}, \mathrm{Chl}_{\mathrm{b}}, \mathrm{Chl}_{\mathrm{T}}$, and $\mathrm{Car}_{\mathrm{T}}$ were determined using the following formulae (Equations (1)-(4)):

$$
\begin{gathered}
\mathrm{Chl}_{\mathrm{a}}\left(\mathrm{mg}^{-1} \mathrm{FW}\right)=\{(12.7 \times(\mathrm{A})-2.69 \times(\mathrm{B})) /(\mathrm{D} \times 1000 \times \mathrm{W})\} \times \mathrm{V} \\
\mathrm{Chl}_{\mathrm{b}}\left(\mathrm{mg} \cdot \mathrm{g}^{-1} \mathrm{FW}\right)=\{(22.9 \times(\mathrm{B})-4.68 \times(\mathrm{A})) /(\mathrm{D} \times 1000 \times \mathrm{W})\} \times \mathrm{V} \\
\mathrm{Chl}_{\mathrm{T}}\left(\mathrm{mg} \cdot \mathrm{g}^{-1} \mathrm{FW}\right)=\{(20.29 \times(\mathrm{B})+8.02 \times(\mathrm{A})) /(\mathrm{D} \times 1000 \times \mathrm{W})\} \times \mathrm{V} \\
\mathrm{Car}_{\mathrm{T}}\left(\mathrm{mg} \cdot \mathrm{g}^{-1} \mathrm{FW}\right)=\left[\left\{\left(1000 \times(\mathrm{C})-1.82\left(\mathrm{Chl}_{\mathrm{a}}\right)-85.02\left(\mathrm{Chl}_{\mathrm{b}}\right)\right) / 198\right\} /(\mathrm{D} \times 1000 \times \mathrm{W})\right] \times \mathrm{V}
\end{gathered}
$$


where FW is fresh weight, $\mathrm{A}$ is the absorbance at $663 \mathrm{~nm}, \mathrm{~B}$ is the absorbance at $645 \mathrm{~nm}, \mathrm{C}$ is the absorbance at $470 \mathrm{~nm}, \mathrm{D}$ is distance travelled by the light path $(1 \mathrm{~cm}), \mathrm{W}$ is weight of the leaf material taken $(0.1 \mathrm{~g})$, and $\mathrm{V}$ is volume of the extract $(10 \mathrm{~mL})$.

\subsection{Determination of Chlorophyll Fluorescence Parameters}

Artificial night light-induced effects on photosystem II (PSII) photochemistry in yellow-poplar leaves were assessed by chlorophyll $a$ fluorescence parameters probed by the chlorophyll $a$ fluorescence transient kinetics. The non-invasive chlorophyll $a$ fluorescence transient test (OJIP transients) was performed with a portable chlorophyll fluorimeter (Pocket PEA, Hansatech Instruments Ltd., Norfolk, UK). The PSII photochemistry assessed by the OJIP transients was determined at diurnal and seasonal points. The fully developed leaves were adapted in darkness for $30 \mathrm{~min}$ on the abaxial surface of freshly detached leaf discs with leaf clips prior to measurement. Thereafter, leaf clips were opened, and samples were illuminated during a 1-s saturating pulse with the intensity of $3500 \mu \mathrm{mol} \cdot \mathrm{m}^{-2} \cdot \mathrm{s}^{-1}$ (peak wavelength at $627 \mathrm{~nm}$ ) for induction of fluorescence red actinic light. Chlorophyll fluorescence parameters that measure the efficiency of PSII photochemistry derived from the OJIP transients were calculated using the pocket PEA software (PEA Plus V1.10, Hansatech Instruments Ltd., UK) according to Strasser et al. [32]. Chlorophyll $a$ fluorescence OJIP transient curves were plotted according to OJIP transients using the following original data: (1) minimal fluorescence intensity $F_{O}$ recorded at $50 \mu \mathrm{s}$ (microseconds) after actinic illumination (O-step, when all PSII RCs are open), (2) fluorescence intensity at $2 \mathrm{~ms}$ (milliseconds) (FJ, J-step), (3) fluorescence intensity at $30 \mathrm{~ms}$ (FI, I-step), and (4) maximal fluorescence intensity FM at 300 ms, the peak P of OJIP (P-step, when all PSII RCs are closed).

Furthermore, the relative variable fluorescence at time $t$, which corresponded to a typical OJIP fluorescence transient, was expressed as $V_{t}=\left(F_{t}-F_{O}\right) /\left(F_{M}-F_{O}\right)$ where $F_{t}$ is the fluorescence at time $t$ after onset of actinic illumination, $\mathrm{F}_{\mathrm{O}}$ is the minimal fluorescence intensity at $50 \mu$ after actinic illumination, and $F_{M}$ is the maximal fluorescence intensity at $300 \mathrm{~ms}$. The appearance in the amplitude of K step in the OJIP can be used for specific indicators of injury to the donor side of PSII, showing differences in the kinetics of OJIP transients between control leaves and artificial night light-treated leaves, $\Delta \mathrm{V}_{\mathrm{t}}=\mathrm{V}_{\mathrm{t}}$ (various levels of artificial night lighting-treated leaves) $-\mathrm{V}_{\mathrm{t}}$ (control leaves).

The photosynthetic performance index $\left(\mathrm{PI}_{\mathrm{ABS}}\right)$ has been used as a key $\mathrm{Chl}_{\mathrm{a}}$ fluorescence parameter that provides useful and quantitative information about the physiological state of plants and their vitality $[32,33]$. The photosynthetic performance index $\mathrm{PI}_{\mathrm{ABS}}$ was also calculated according to the combined measurement of three independent functional steps of OJIP transients (Equation (5)): the fraction of reaction center per chlorophyll of the antenna (RC/ABS), the contribution of the light reactions for primary photochemistry $\left[\varphi \mathrm{P}_{\mathrm{O}} /\left(1-\varphi \mathrm{P}_{\mathrm{O}}\right)\right]$ and the contribution of electron transport beyond electron acceptors of PSII (primary quinone), $Q_{A}\left[\psi E_{O} /\left(1-\psi E_{O}\right)\right]$.

$$
\mathrm{PI}_{\mathrm{ABS}}=(\mathrm{RC} / \mathrm{ABS}) \times\left(\varphi \mathrm{P}_{\mathrm{O}} /\left(1-\varphi \mathrm{P}_{\mathrm{O}}\right)\right) \times\left(\psi \mathrm{E}_{\mathrm{O}} /\left(1-\psi \mathrm{E}_{\mathrm{O}}\right)\right)
$$

where $\mathrm{RC}, \mathrm{ABS}, \varphi \mathrm{Po}$ and $\psi$ Eo represent the reactive center, the light energy for absorption, the maximal quantum yield of primary photochemistry (i.e., the excitons trapped per photon absorbed), and the excitation efficiency for electron transport beyond $\mathrm{Q}_{\mathrm{A}}{ }^{-}$, respectively [32].

\subsection{Determination of Photosynthetic Gas Exchange}

Photosynthetic properties (i.e., Pn: net photosynthetic rate, Gs: stomatal conductance, Tr: transpiration rate, and ratio of intercellular $(\mathrm{Ci})$ to atmospheric $(\mathrm{Ca}) \mathrm{CO}_{2}$ concentration, $\left.\mathrm{Ci} / \mathrm{Ca}\right)$ were measured with a LI-6400XT portable photosynthesis system (Li-Cor Inc., Lincoln, NE, USA) fitted with a 6400-02B red/blue LED light source. The measurements were taken on the third to fifth fully expanded leaves from the top of each plant for each treatment.

All gas exchange measurements were conducted with the $\mathrm{CO}_{2}$ concentration set at $400 \mu \mathrm{mol} \cdot \mathrm{mol}^{-1}$, at air temperature of $25^{\circ} \mathrm{C}$ and relative humidity of $50-60 \%$. Photosynthetic photon 
flux density (PPFD, $\mu \mathrm{mol} \cdot \mathrm{m}^{-2} \cdot \mathrm{s}^{-1}$ ) was adjusted to ambient levels determined outside the treatments immediately prior to initiation of the sampling procedure. Photosynthetic water use efficiency (WUE, the ratio of photosynthetic rate to transpiration rate) was calculated using the following formula (6) [34]:

$$
\text { WUE }\left(\mu \mathrm{mol} \cdot \mathrm{mmol}^{-1}\right)=\left(\operatorname{Pn}\left(\mu \mathrm{mol} \cdot \mathrm{m}^{-2} \cdot \mathrm{s}^{-1}\right)\right) /\left(\operatorname{Tr}\left(\mathrm{mmol} \cdot \mathrm{m}^{-2} \cdot \mathrm{s}^{-1}\right)\right)
$$

where Pn is the photosynthetic rate $\left(\mu \mathrm{mol} \cdot \mathrm{m}^{-2} \cdot \mathrm{s}^{-1}\right)$ and $\operatorname{Tr}$ is the transpiration rate $\left(\mathrm{mmol} \cdot \mathrm{m}^{-2} \cdot \mathrm{s}^{-1}\right)$.

Diurnal patterns of photosynthetic parameters were evaluated by intervals of $3 \mathrm{~h}$ from 06:00 to 02:00 after the 4- and 13-month treatment from initial exposure on 1 May 2013. Seasonal trends of photosynthetic capacity were also examined from 08:30 to 11:30 at 1, 2, 3, 5, and 8 weeks after initial onset of treatments on 22 April 2014.

\subsection{Quantification of Oxidative Stress and Enzyme Activity}

Fully expanded leaves exposed to each treatment were collected from yellow-poplar seedlings grown under the presence/absence of artificial night lighting over three years. Leaf discs were punched out with a cork borer $(2 \mathrm{~cm}$ in diameter) to obtain leaf discs of similar size from the central area of the fully developed leaf. The formation of in situ superoxide anion radical $\left(\mathrm{O}_{2}{ }^{-}\right)$was estimated using the dye nitroblue tetrazolium (NBT; N5514, Sigma-Aldrich, Saint Louis, MO, USA) as described by Dutilleul et al. [35] and Lin et al. [36] with minor modification. Leaf discs were vacuum-infiltrated in $0.5 \mathrm{mg} \cdot \mathrm{mL}^{-1} \mathrm{NBT}$ prepared in $10 \mathrm{mM}$ potassium phosphate buffer $(\mathrm{pH} 7.8)$ for $15 \mathrm{~min}$ and then incubated at room temperature in the dark until the dark blue insoluble formazan produced by the reaction of NBT with $\mathrm{O}_{2}{ }^{-}$became visible. After staining, the discs were then cleaned in a 9:1 mixture of ethanol and glycerin at $70{ }^{\circ} \mathrm{C}$ to eliminate the background green color completely. Samples were stored in $70 \%$ glycerol for microscopic observation.

In situ hydrogen peroxide $\left(\mathrm{H}_{2} \mathrm{O}_{2}\right)$ was visually detected using 3,3'-diaminobenzidine (DAB; D5905, Sigma-Aldrich, Saint Louis, MO, USA) by a modified version of a method in previously described Daudi et al. [37]. Leaf disks were quickly submerged and vacuum-infiltrated in $1 \mathrm{mg} \cdot \mathrm{mL}^{-1}$ $\mathrm{DAB}(\mathrm{pH}$ 3.8) for $15 \mathrm{~min}$ and then incubated in the dark using aluminum foil at room temperature for 4-5 h. After staining of the leaf discs, leaf samples were immersed in a bleaching solution (ethanol:acetic acid:glycerol = 3:1:1) and then heated in a water bath at $95^{\circ} \mathrm{C}$ for 15 min to eliminate the background pigments. $\mathrm{H}_{2} \mathrm{O}_{2}$ was directly visualized as reddish-brown spots at the site of DAB polymerization. After boiling, leaf discs were replaced and stored in the fresh bleaching solution. Thereafter, histochemical localization sites of $\mathrm{O}_{2}{ }^{-}$and $\mathrm{H}_{2} \mathrm{O}_{2}$ in NBT- and DAB-stained samples were observed using a stereomicroscope (Leica MZ75, Leica Microsystems, Wetzlar, Germany) coupled with a digital camera (Leica DFC 490, Leica Microsystems, Wetzlar, Germany) focused directly on the computer screen. To quantify the NBT- or DAB-stained areas, digital images of leaf discs were converted into grayscale images and NBT- or DAB-stained spot areas were determined as a percentage of NBT- or DAB-stained spot areas to the total leaf disc areas with WinFOLIA PRO 2013 software (WinFOLIA, Regent Instruments, Québec, QC, Canada).

Freshly harvested leaf samples were immediately frozen in liquid nitrogen. Superoxide dismutase (SOD) activity was spectrophotometrically measured at $450 \mathrm{~nm}$ with a SOD Assay Kit (Sigma 19160, Sigma-Aldrich, Saint Louis, MO, USA) according to the manufacturer's instructions provided by Sigma-Aldrich. The SOD Assay Kit utilizes a water-soluble tetrazolium salt that produces a formazan dye upon reduction with $\mathrm{O}_{2}{ }^{-}$. The rate of reduction is linearly related to the xanthine oxidase (XO) activity, and it is inhibited by SOD. Therefore, the SOD activity (50\% inhibition activity of SOD) can be colorimetrically determined by measuring the decrease in the color development at $450 \mathrm{~nm}$.

\subsection{Lipid Peroxidation and Membrane Permeability}

The Malondialdehyde (MDA) contents were assayed as an end-product of lipid peroxidation by thiobarbituric acid (TBA) reaction. Freshly harvested leaf samples were immediately frozen in liquid 
nitrogen, and ground into powder. Leaf samples $(0.2 \mathrm{~g})$ were homogenized in $2 \mathrm{~mL}$ of $10 \%(w / v)$ trichloroacetic acid (TCA). The homogenate was centrifuged at $12,000 \times g$ for $10 \mathrm{~min}$ and $4 \mathrm{~mL} \mathrm{of} 10 \%$ TCA containing $0.5 \%(w / v)$ TBA was added to $1 \mathrm{~mL}$ of supernatant. The mixture was heated in a boiling water bath at $95^{\circ} \mathrm{C}$ for $15 \mathrm{~min}$ and then immediately cooled in an ice bucket to stop the reaction. Then samples were centrifuged at $12,000 \times \mathrm{g}$ for $10 \mathrm{~min}$ and the absorbance of the supernatant was measured at $450 \mathrm{~nm}, 532 \mathrm{~nm}$, and $600 \mathrm{~nm}$ by a UV spectrophotometer. MDA contents $\left(\mu \mathrm{mol} \cdot \mathrm{g}^{-1} \mathrm{FW}\right)$ were calculated using the following formula (Equation (7)):

$$
\operatorname{MDA}=\left(6.45\left(\mathrm{~A}_{532}-\mathrm{A}_{600}\right)-0.56\left(\mathrm{~A}_{450}\right)\right) \times(\mathrm{V} / \mathrm{FW})
$$

where A450, A532, and A600 refer to the absorbance at the wavelength of $450 \mathrm{~nm}, 532 \mathrm{~nm}$, and $600 \mathrm{~nm}$, respectively, $\mathrm{V}$ is the volume (L) of the extract, and FW is the fresh weight $(\mathrm{g})$ of the sample.

Leaf electrolyte leakage was measured to assess membrane permeability. Freshly harvested leaf samples were rinsed three times with ultra-pure deionized water to remove surface contaminants. Fifteen freshly cut leaf discs $(0.5 \mathrm{~cm})$ were prepared from leaves using a cork borer and placed in a glass vial containing $50 \mathrm{~mL}$ of ultra-pure deionized water at room temperature for $6 \mathrm{~h}$. The electrolyte leakage in the solution $\left(\mathrm{EC}_{1}\right)$ was measured by a conductivity meter (S230, Mettler-Toledo International Inc., Schwerzenbach, Switzerland). Subsequently, these materials were heated in boiling water for $15 \mathrm{~min}$ and then quickly cooled at room temperature, and the total electrical conductivity was measured again $\left(\mathrm{EC}_{2}\right)$. The relative permeability of leaf plasma membrane was expressed as a percentage of total electrolytes (Equation (8)):

$$
\text { Electrolyte leakage }(\%)=\mathrm{EC}_{1} / \mathrm{EC}_{2} \times 100
$$

where $\mathrm{EC}_{1}$ is the electrolytic conductivity of the solution at $6 \mathrm{~h}$ before heating and $\mathrm{EC}_{2}$ is the electrolytic conductivity of the solution after heating.

\subsection{Measurement of Water Status and Plant Growth}

Relative water content (RWC) was determined using the method of Nishiyama et al. [38]. Five leaf discs of $11 \mathrm{~mm}$ diameter were punched using a cork borer. Detached aerial parts were individually weighed to obtain fresh weight (FW). After the initial determination of the sample fresh weight, individual samples were placed into $50 \mathrm{~mL}$ tubes and hydrated overnight in $50 \mathrm{~mL}$ of ultra-pure deionized water to full turgidity at $4{ }^{\circ} \mathrm{C}$ in darkness. Then, leaf discs were taken out of water and leaf surface moisture was gently and quickly removed with filter paper, and samples were immediately weighed to determine their turgid weight (TW). Subsequently, dry weights were recorded after drying these discs at $65^{\circ} \mathrm{C}$ for $48 \mathrm{~h}$ (DW). The RWC was determined according to the following formula (Equation (9)):

$$
\operatorname{RWC}(\%)=(\mathrm{FW}-\mathrm{DW}) /(\mathrm{TW}-\mathrm{DW}) \times 100
$$

where FW is the fresh weight, DW is the dry weight after drying samples at $65^{\circ} \mathrm{C}$ for $48 \mathrm{~h}$, and TW is the turgid weight after hydrating samples for overnight at $4{ }^{\circ} \mathrm{C}$ in darkness.

Artificial night lighting effects on aboveground and belowground plant biomass were recorded at the beginning and end of artificial night lighting treatments. After the experiment was finished, five plants per each treatment were harvested. Total weight of each plant was measured, then weight of aboveground and belowground portions of each plant were also measured. Subsequently, all materials were then oven-dried at $70{ }^{\circ} \mathrm{C}$ until a constant weight was achieved, and then weighed to determine the total aboveground and belowground dry weight.

\subsection{Statistical Analysis}

Statistically significant differences among treatments were determined using one-way analysis of variance (ANOVA) followed by Tukey's test for multiple comparisons. All statistical analyses 
were performed using IBM SPSS Statistics Version 22 software package (SPSS Inc., IBM Company Headquarters, Chicago, IL, USA). Data were presented as means \pm standard deviation (SD).

\section{Results}

\subsection{Seasonal Patterns in Photosynthetic Pigments}

Figure 1 depicts the variation of main photosynthetic pigment values from the controls in yellow-poplar seedlings grown under different night-interruption by artificial night lighting. $\mathrm{Chl}_{\mathrm{a}}$, $\mathrm{Chl}_{\mathrm{b}}, \mathrm{Chl}_{\mathrm{T}}$, and $\mathrm{Car}_{\mathrm{T}}$ showed different degrees of reduction depending on artificial night lighting. As shown in Figure 1A, Chl after 122 days of the experiment in 2013 was markedly decreased by $32 \%$ and $38 \%$ in $\mathrm{T} 2$ and $\mathrm{T} 3$, respectively $\left(\mathrm{F}_{3,16}=22.375, p<0.001\right)$, showing no statistically significant difference between $\mathrm{C} 0$ and T1. Remarkably, $\mathrm{Chl}_{\mathrm{a}}$ contents in 2014 were significantly reduced by $32 \%, 48 \%$, and $50 \%$ in $\mathrm{T} 1, \mathrm{~T} 2$, and $\mathrm{T} 3$, respectively, as compared to those of control $\left(\mathrm{F}_{3,16}=200.187\right.$, $p<0.001)$. $\mathrm{Ch}_{\mathrm{b}}$ in 2013 was significantly reduced by $19 \%, 33 \%$, and $51 \%$ in $\mathrm{T} 1, \mathrm{~T} 2$, and $\mathrm{T} 3$, respectively, compared with that of control $\left(\mathrm{F}_{3,16}=16.052, p<0.001\right)$. In contrast, $\mathrm{Chl}_{\mathrm{b}}$ in 2014 showed significant increase by 2.23-, 0.68-, and 1.03-fold in T1, T2, and T3, respectively, as compared with that of control $\left(\mathrm{F}_{3,16}=44.088, p<0.001\right) . \mathrm{Chl}_{\mathrm{T}}$ contents in 2013 and 2014 decreased in the day /night with artificial lighting cycle, especially in $\mathrm{T} 2$ and $\mathrm{T} 3$ (Figure $1 \mathrm{~B}$ ). Compared to $\mathrm{Chl}_{\mathrm{T}}$ contents of control, $\mathrm{Ch}_{\mathrm{T}}$ contents in 2013 showed significant reductions in $\mathrm{T} 2$ and $\mathrm{T} 3$ by 32\% and $41 \%$, respectively, whereas there was no significant difference in T1. Moreover, ChlT contents in 2014 were significantly reduced by $21 \%, 41 \%$, and $42 \%$ in $\mathrm{T} 1, \mathrm{~T} 2$, and $\mathrm{T} 3$, respectively, as compared to those of control $\left(\mathrm{F}_{3,16}=142.054\right.$, $p<0.001)$. The ratio of $\mathrm{Chl}_{\mathrm{a}}$ to $\mathrm{Chl}_{\mathrm{b}}\left(\mathrm{Chl}_{\mathrm{a}} / \mathrm{Chl}_{\mathrm{b}}\right)$ in the leaves of yellow-poplar plants in 2013 was statistically increased in the highest level (T3) of artificial night lighting than those in the control (Figure $1 \mathrm{C} ; \mathrm{F}_{3,16}=16.086, p<0.001$ ). In contrast, the $\mathrm{Chl}_{\mathrm{a}} / \mathrm{Chl}_{\mathrm{b}}$ ratio in 2014 was markedly reduced by $69 \%, 65 \%$, and $67 \%$ below the control in $\mathrm{T} 1, \mathrm{~T} 2$, and $\mathrm{T} 3$, respectively $\left(\mathrm{F}_{3,16}=363.079, p<0.001\right)$. The ratio of $\mathrm{Chl}_{\mathrm{a}}$ to $\mathrm{Chl}_{\mathrm{T}}\left(\mathrm{Chl}_{\mathrm{a}} / \mathrm{Chl}_{\mathrm{T}}\right)$ was significantly increased by $6 \%$ of control in leaves exposed to the highest level (T3) of artificial night lighting compared to the natural night condition in 2013 (Figure 1D), but there were no significant differences in $\mathrm{T} 1$ and $\mathrm{T} 2$. In contrast, the $\mathrm{Chl}_{\mathrm{a}} / \mathrm{Ch}_{\mathrm{T}}$ in 2014 decreased by approximately $14 \%, 12 \%$, and $13 \%$ in $\mathrm{T} 1$, $\mathrm{T} 2$, and $\mathrm{T} 3$, respectively $\left(\mathrm{F}_{3,16}=75.985\right.$, $p<0.001)$. Under artificial night lighting conditions, the ratio of $\mathrm{Chl}_{\mathrm{b}}$ to $\mathrm{Chl}_{\mathrm{T}}\left(\mathrm{Chl}_{\mathrm{b}} / \mathrm{Chl}_{\mathrm{T}}\right)$ in 2013 was significantly decreased in the highest level (T3) of artificial night lighting compared with that of control (Figure 1D; $\mathrm{F}_{3,16}=12.626, p<0.001$ ). The values of $\mathrm{Chl}_{\mathrm{b}} / \mathrm{Chl}_{\mathrm{T}}$ in 2014 were 2.81-, 0.91-, and 1.04-fold in $\mathrm{T} 1, \mathrm{~T} 2$, and T3, respectively, as compared with those of control $\left(\mathrm{F}_{3,16}=75.985, p<0.001\right)$. Carotenoids $\left(\mathrm{Car}_{\mathrm{T}}\right)$ in the leaves of the T3 treatment in 2013 slightly decreased by $17 \%\left(\mathrm{~F}_{3,16}=5.214, p=0.006\right)$ below the control, showing no statistically significant difference in T1 and T2 (Figure 1B). In contrast, Car decreased significantly by $10 \%, 25 \%$, and $31 \%$ in T1, T2, and T3, respectively, below that of control $\left(\mathrm{F}_{3,16}=78.042, p<0.001\right)$. Under artificial night lighting, the ratio of $\mathrm{Car}_{\mathrm{T}}$ to $\mathrm{Chl}_{\mathrm{T}}\left(\mathrm{Car}_{\mathrm{T}} / \mathrm{Chl}_{\mathrm{T}}\right)$ in 2013 significantly increased by $15 \%, 45 \%$, and $40 \%$ in T1, T2, and T3, respectively, as compared to that of control (Figure 1C; $\mathrm{F}_{3,16}=87.217, p<0.001$ ). Similarly, the values of $\mathrm{Car}_{\mathrm{T}} / \mathrm{Chl}_{\mathrm{T}}$ in 2014 showed a significant increase by $14 \%, 27 \%$, and $19 \%$ in $\mathrm{T} 1, \mathrm{~T} 2$, and $\mathrm{T} 3$, respectively, as compared with that of control $\left(\mathrm{F}_{3,16}=44.201, p<0.001\right)$. 


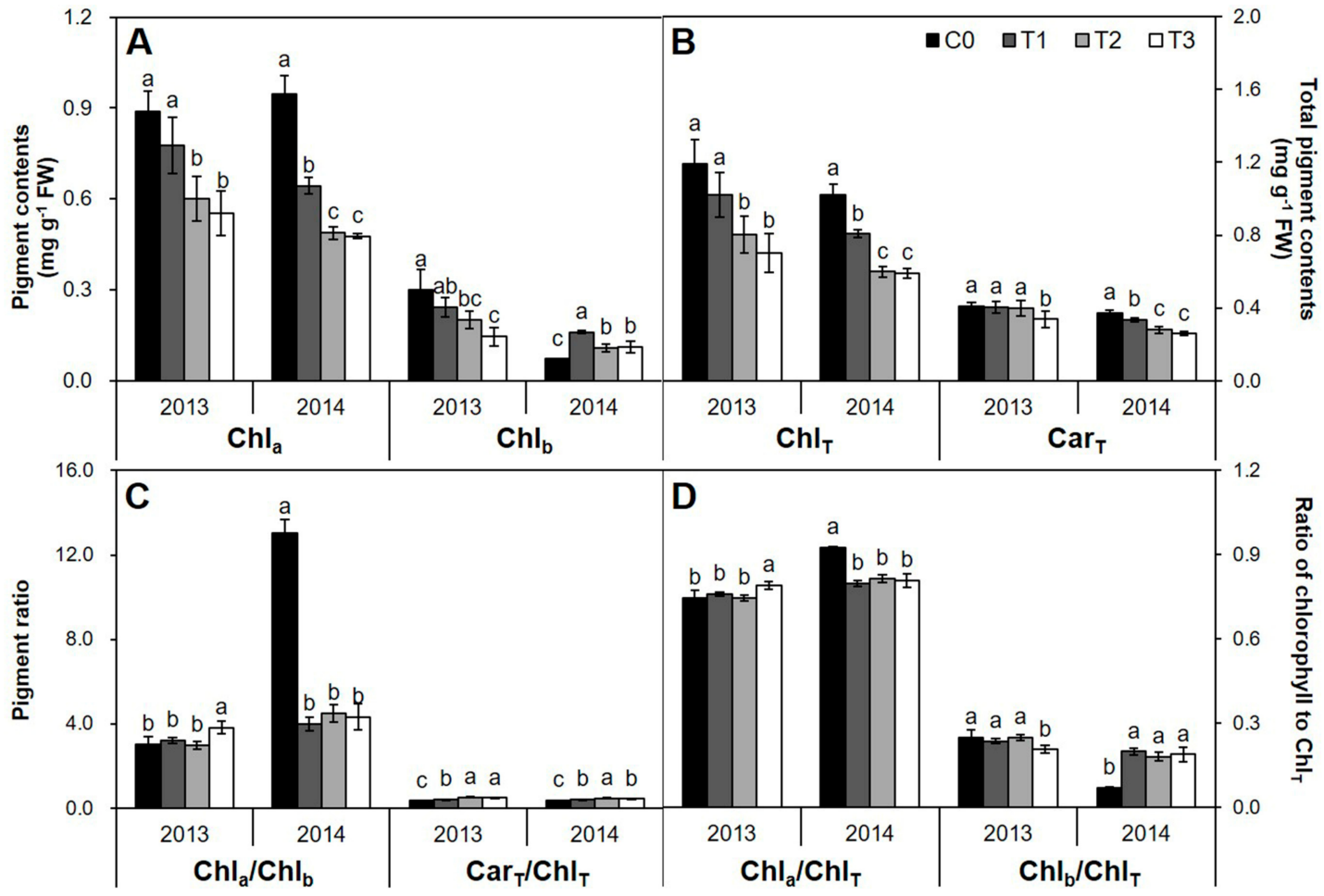

Figure 1. Pigment contents $\left((\mathbf{A}), \mathrm{Chl}_{\mathrm{a}}\right.$ and $\left.\mathrm{Chl}_{\mathrm{b}}\right)$, total pigment contents $\left((\mathbf{B}), \mathrm{Chl}_{\mathrm{T}}\right.$ and $\left.\mathrm{Car}_{\mathrm{T}}\right)$, pigment ratio $\left((\mathbf{C}), \mathrm{Chl}_{\mathrm{a}} / \mathrm{Chl}_{\mathrm{b}}\right.$ and $\left.\mathrm{Car}_{\mathrm{T}} / \mathrm{Chl}_{\mathrm{T}}\right)$, and ratio of $\mathrm{Chl}_{\mathrm{a}}$ or $\mathrm{Chl}_{\mathrm{b}}$ to $\mathrm{Chl}_{\mathrm{T}}\left((\mathbf{D}), \mathrm{Chl}_{\mathrm{a}} / \mathrm{Chl}_{\mathrm{T}}\right.$ and $\left.\mathrm{Chl}_{\mathrm{b}} / \mathrm{Chl}_{\mathrm{T}}\right)$ in yellow-poplar leaves exposed to the natural day/night cycle ( $\mathrm{C} 0$, black bars) and the day/night with artificial lighting cycle (T1, T2, and T3 denote dark gray bars, light gray bars, and white bars, respectively). Data indicate the mean $\pm \operatorname{SD}(n=5)$. Different lowercase letters on the bars indicate significant differences among treatments in 2013 and 2014, respectively (Tukey's test after one-way ANOVA); FW = fresh weight.

\subsection{Diurnal and Seasonal Patterns in PSII Photochemistry}

To investigate photosystem II (PSII) photochemical effects of artificial night lighting on plants, chlorophyll $a$ fluorescence as a tool for biofeedback control of the photochemistry of PSII was monitored over diurnal and seasonal timescales in plants exposed to artificial HPS night lighting. Figure 2 shows all the steps of the chlorophyll $a$ fluorescence transient, $\mathrm{O}, \mathrm{K}, \mathrm{J}, \mathrm{I}$, and $\mathrm{P}$, thus confirming that $\mathrm{K}$ and $\mathrm{J}$ steps are a different phenomenon for each treatment. The plants exposed at $\mathrm{C} 0$ exhibited typical fluorescence transient curves. However, plants grown under T1, T2, and T3 displayed the imbalance with the characteristic chlorophyll $a$ fluorescence transient (OJIP) steps. As shown in Figure 2, it can be observed that $\mathrm{F}_{\mathrm{O}}$ and $\mathrm{F}_{\mathrm{K}}$ display significant increases at $\mathrm{T} 1, \mathrm{~T} 2$, and $\mathrm{T} 3$, with their highest values measured in the leaf discs exposed to T3 at 08:00 and 11:30. For the fluorescence intensity at step J (FJ), the greatest values were identified in T3 at 08:00 and 11:30. The fluorescence intensity at step I (FI) and the maximum fluorescence (FM) displayed a significant decrease at the beginning of leaf exposure by artificial night lighting with the lowest values. Under chlorophyll fluorescence-based biofeedback systems, the artificial night lighting-induced leaves exhibited different depressions at OJIP step.

Chlorophyll $a$ fluorescence rises at J-, I-, and P-step showed enhanced depression in artificial night lighting-induced leaves, especially in T3. T1, T2, and T3 in artificial night lighting regimes had a large rise at K-step and a significant effect on fluorescent transients, especially I- and P-step. However, there was a greater decline at all steps of OJIP of yellow-poplar leaves grown under T1, T2, and T3 with artificial night lighting, as compared with those of control without artificial night lighting. The $\mathrm{K}$ step (i.e., the fluorescence intensities at $300 \mu \mathrm{s}$ ) in $\Delta \mathrm{V}_{\mathrm{t}}$ curves increased significantly in 
all artificial night lighting-induced treatments (Figure 2B,D,F,H,J), which indicates that the acceptor side activity was inhibited during the artificial night lighting treatment. The parameters relative to activities of PSI and PSII in plants exposed to artificial night lighting were measured using the leaves from plants treated for two years. These results indicate that the donor side activity of PSII was inhibited in yellow-poplar grown under artificial night lighting.

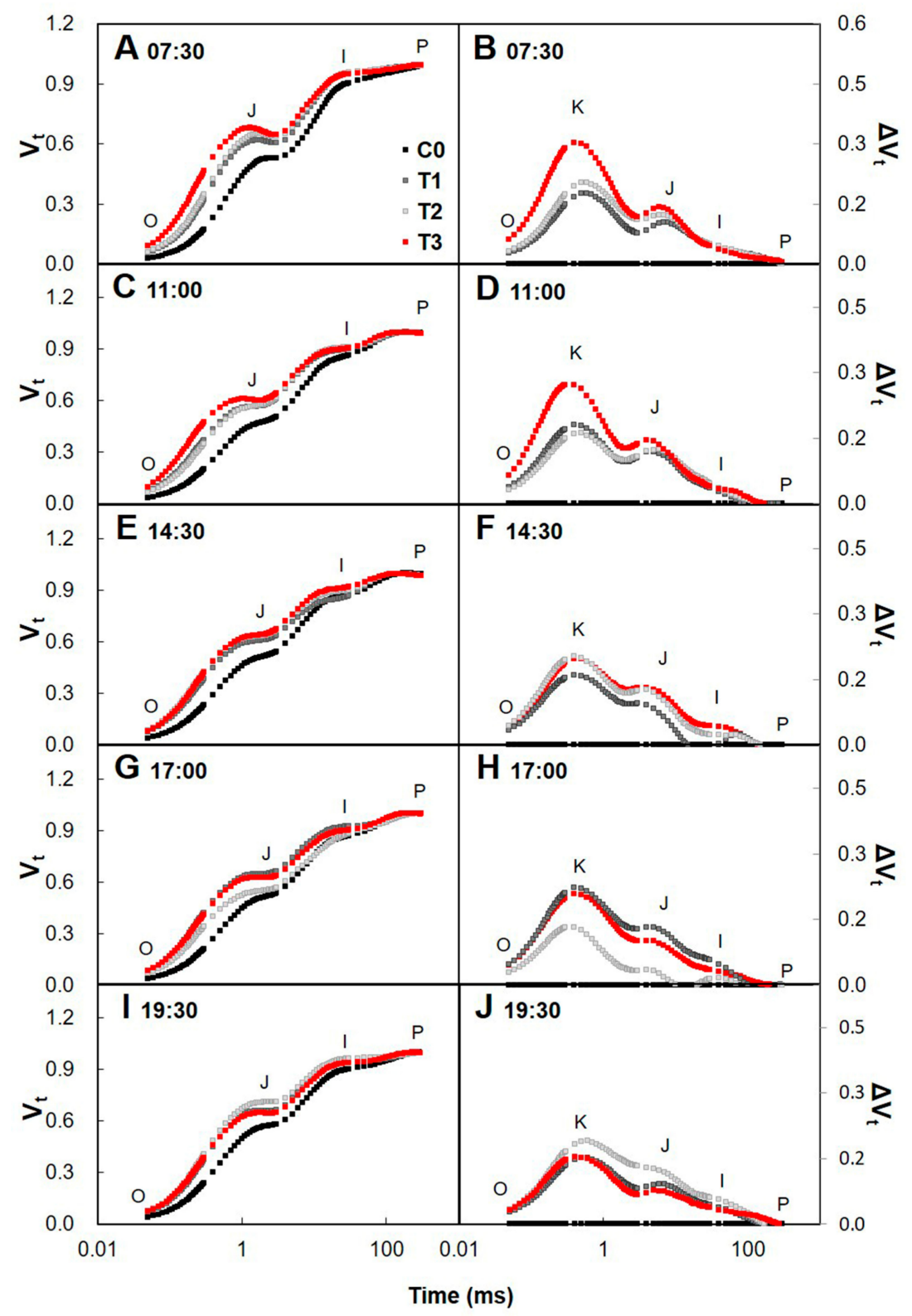

Figure 2. Comparison of Chlorophyll $a$ fluorescence (OJIP) transients of control (C0, natural day/night cycle) and the day/night with artificial lighting cycle (T1, T2, and T3) after two years of artificial night lighting treatment. OJIP transients were induced by a $1 \mathrm{~s}$ light pulse of $3500 \mu \mathrm{mol} \cdot \mathrm{m}^{-2} \cdot \mathrm{s}^{-1}$. (A,C,E,G,I) Represent relative fluorescence kinetics $\left(\mathrm{V}_{\mathrm{t}}\right)$ and $(\mathbf{B}, \mathbf{D}, \mathbf{F}, \mathbf{H}, \mathbf{J})$ represent $\Delta \mathrm{V}_{\mathrm{t}}$ (different kinetics of OJIP transients) among treatments at 07:30, 11:00, 14:30, 17:00 and 19:30, respectively. $\mathrm{V}_{\mathrm{t}}$ at time $\mathrm{t}$ derived from the mean OJIP transients between $F_{O}$ and Fm, was defined as: $V_{t}=\left(F_{t}-F_{O}\right) /\left(F_{M}-F_{O}\right) . \Delta V_{t}$ refer to differences of the $V_{t}$ of all cases.

To further confirm whether artificial night lighting contributed to seasonal changes in photosynthetic function, $\mathrm{Ls}, \mathrm{Pn}, \mathrm{PI}_{\mathrm{ABS}}$, and Fv / Fm were evaluated throughout the 4-, 13-, and 28-month period after artificial night lighting treatments (Figure 3). As shown in Figure $3 \mathrm{~A}, \mathrm{PI}_{\mathrm{ABS}}$ on seasonal 
patterns was significantly reduced by $40 \%, 56 \%$, and $67 \%$, respectively, in plants receiving artificial night lighting (T1, T2, and T3) compared with that of control after 28 months $\left(\mathrm{F}_{3,16}=7.869, p=0.002\right)$. However, no statistically significant differences were noted at 4 months and 13 months among treatments. For Fv/Fm (Figure 3B), there was no significant difference among treatments at 4 months and 13 months. In contrast, $\mathrm{PI}_{\mathrm{ABS}}$ after 28 months showed a significant difference among treatments $\left(\mathrm{F}_{3,16}=3.404, p=0.043\right)$.

Stomatal limitation $\left(\mathrm{L}_{\mathrm{S}}\right)$ showed statistically significant increase under artificial night lighting, especially in T3, over $4\left(\mathrm{~F}_{3,16}=4.788, p=0.015\right), 13\left(\mathrm{~F}_{3,16}=4.958, p=0.013\right)$, and $28\left(\mathrm{~F}_{3,16}=16.276\right.$, $p<0.001$ ) months after treatments (Figure 3C). Furthermore, photosynthetic rates (Pn) showed significant increase in T1 after 4 months $\left(\mathrm{F}_{3,16}=14.101, p<0.001\right)$ and a significant decrease in $\mathrm{T} 2$ and $\mathrm{T} 3$ after 13 months $\left(\mathrm{F}_{3,16}=9.713, p=0.001\right)$. In contrast, Pn showed significant reductions in plants exposed to artificial night lighting after 28 months, especially in T3 (Figure 3D; $F_{3,16}=30.385$, $p<0.001)$. To further evaluate whether artificial night lighting elicits any alterations on chlorophyll $a$ fluorescence parameters during a diurnal cycle, the parameters of the chlorophyll fluorescence transient were measured every $3 \mathrm{~h}(07: 30,11: 00,14: 30,17: 00$ and 19:30) during diurnal hours after two years of the day/night with artificial lighting cycle.

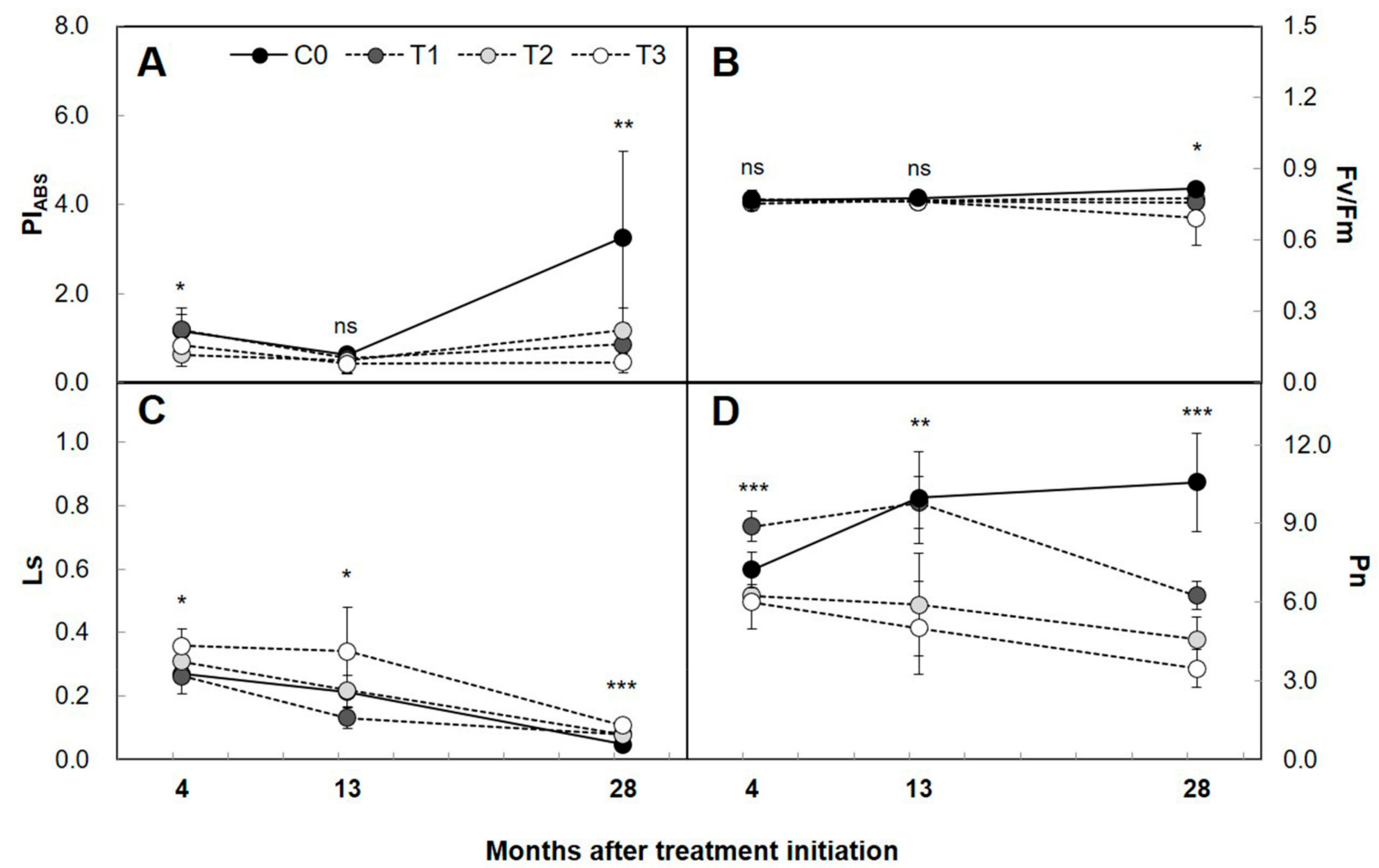

Figure 3. Seasonal changes of photosynthetic function in yellow-poplar leaves treated with artificial night lighting. (A) Performance index (potential) for energy conservation from photons absorbed by PSII antenna to the reduction of $\mathrm{Q}_{\mathrm{B}}\left(\mathrm{PI}_{\mathrm{ABS}}\right)$; (B) fluorescence-based maximum quantum yield of photosystem II photochemistry $(\mathrm{Fv} / \mathrm{Fm})$; (C) stomatal limitation to photosynthesis $\left(\mathrm{L}_{\mathrm{S}}=1-\mathrm{Ci} / \mathrm{Ca}\right)$; (D) photosynthetic rate $\left(\mathrm{Pn}, \mu \mathrm{mol} \cdot \mathrm{m}^{-2} \cdot \mathrm{s}^{-1}\right)$ of yellow-poplar plants exposed to the natural day/night cycle (C0) and the day/night with artificial lighting cycle (T1, T2, and T3) during the experimental period. The black solid circles $(\bullet)$, gray solid circles $(\bullet)$, light gray solid circles $(\bullet)$, and hollow circles $(\bigcirc)$ represent $\mathrm{C} 0, \mathrm{~T} 1, \mathrm{~T} 2$, and T3, respectively. The $x$-axis represents the months after treatment initiation at 1 May 2013. Data points represent mean \pm SD of five experimental replicates. Asterisks represent significant treatment effects at a single measuring date $\left({ }^{*} p<0.05 ;{ }^{* *} p<0.01\right.$; ${ }^{* * *} p<0.001$; ns, not significant). 
The energy flux parameters of absorption, dissipation, and trapping per reaction center (RC) of PSII at the level of the antenna chlorophyll, defined as ABS/RC (apparent antenna size of active PSII $\mathrm{RC}$ ), DIO/RC (dissipated energy flux per RC at $\mathrm{t}=0$ ), and TRO/RC (trapping flux leading to QA reduction per $\mathrm{RC}$ ), respectively, showed a statistically significant improvement in leaves exposed to artificial night lighting at 07:30, 11:00, 14:30 and 17:00, but ETO/RC (electron transport flux per RC at $t=0$ ), electron transport per reaction center $(R C)$ of PSII, was greater at 07:30 compared with that of control. In phenomenological energy fluxes, ETO/CS as electron transport per cross section (CS) was only found to be significantly reduced in the leaves exposed to artificial night lighting over all time scales.

More specifically, $\mathrm{PI}_{\mathrm{ABS}}, \mathrm{RC} / \mathrm{ABS}, \varphi \mathrm{P}_{\mathrm{O}} /\left(1-\varphi \mathrm{P}_{\mathrm{O}}\right)$, and $\psi \mathrm{E}_{\mathrm{O}} /\left(1-\psi \mathrm{E}_{\mathrm{O}}\right)$ as vitality indexes of the photosynthetic organisms in diurnal changes in the parameters of performance index induced a significant decrease in artificial night lighting at 07:30, 11:00, 14:30 and 17:00, except for the $\varphi \mathrm{P}_{\mathrm{O}} /\left(1-\varphi \mathrm{P}_{\mathrm{O}}\right)$, which presented no significant reduction at 17:00. In addition, $\varphi \mathrm{E}_{\mathrm{O}}, \psi \mathrm{E}_{\mathrm{O}}$, and $\mathrm{RC} / \mathrm{CS}$ also decreased significantly in artificial night lighting treatments across all time points, however, $\varphi \mathrm{P}_{\mathrm{O}}$ showed statistically significant variations in T3 at 07:30 and 11:00 compared with that of control. The $\mathrm{PI}_{\mathrm{ABS}}$, a combination of three partial components, is one of the chlorophyll fluorescence parameters that provide useful and quantitative information about the physiological state of plants and their vitality [32]. Data showed that $\mathrm{PI}_{\mathrm{ABS}}$ was a highly sensitive parameter and changed significantly under artificial night lighting. The reduction of $\mathrm{PI}_{\mathrm{ABS}}$ on diurnal patterns was higher in $\mathrm{T} 1, \mathrm{~T} 2$, and $\mathrm{T} 3$ with artificial night lighting, as compared with that of control without artificial night lighting at 07:30, 11:00, and 14:30, showing no statistically significant difference between T1 and control at 19:30. In seasonal patterns, the flux of absorption, trapping, and dissipation per reaction center (RC) of PSII, defined as ABS/RC, TRO/RC, and DIO/RC, respectively, were significantly greater in yellow-poplar leaves exposed to artificial night lighting (T1, T2, and T3) during the 28-month treatment period. Electron transport flux per RC of PSII defined as ETO/RC began increasing at artificial night lighting of T1. This value was similar to that of T2, but it was lower than the value obtained in T3.

\subsection{Diurnal and Seasonal Patterns of Photosynthetic Activity}

To determine diurnal and seasonal variations in photosynthetic parameters, yellow-poplar leaves were measured every $4 \mathrm{~h}$ and $3 \mathrm{~h}$ after 4 months and 13 months of artificial night lighting, respectively (Figures 4 and 5). Over the course of the diurnal cycle, there was a significant circadian variation in leaf gas exchange parameters. Moreover, photosynthetic parameters showed different diurnal patterns among treatments after 4 months and 13 months. Diurnal changes of the net photosynthetic rate (Pn), stomatal conductance (Gs), and transpiration rate (Tr) revealed a unimodal pattern after 4 months (Figure $4 \mathrm{~A}-\mathrm{C}$ ). The Pn revealed a statistically significant difference among treatments occurring at 02:00 $\left(\mathrm{F}_{3,16}=59.916, p<0.001\right), 06: 00\left(\mathrm{~F}_{3,16}=3.489, p<0.040\right), 10: 00\left(\mathrm{~F}_{3,16}=14.278\right.$, $p<0.001), 18: 00\left(\mathrm{~F}_{3,16}=8.823, p=.001\right)$, and 22:00 $\left(\mathrm{F}_{3,16}=6.002, p=0.006\right)$. In addition, Pn was reduced under T2 and T3 with artificial lighting at 06:00, 10:00, and 18:00. However, there was no statistically significant difference in Pn at 14:00. Diurnally, maximum values of Pn were generally shown at 10:00, and thereafter they decreased to low levels at 18:00 under daylight. Remarkably, Pn at 10:00 showed significant increase by $23 \%$ in T1 compared with that of C0 (Figure 4A). Eventually, leaves exposed to artificial night lighting, especially in $\mathrm{T} 2$ and in T3, showed a lower nighttime respiration rate at 02:00 due to reduced nighttime stomatal conductance and transpiration (Figure 4B,D).

At 13 months after the exposure of artificial night lighting, there was a similar trend in diurnal variations of Pn between C0 and T1 (Figure 5A). In the present study, Pn presented bimodal peaks in yellow-poplar leaves of $\mathrm{C} 0$ and $\mathrm{T} 1$ after 13 months of treatments; however, diurnal variation of $\mathrm{Pn}$ in T2 and T3 revealed a unimodal pattern. On the other hand, Gs and Tr showed similar patterns over diurnal hours (Figure $5 B, C$ ). Pn revealed statistically significant differences among treatments at 02:00 $\left(\mathrm{F}_{3,16}=32.681, p<0.001\right), 06: 00\left(\mathrm{~F}_{3,16}=8.935, p=0.001\right), 09: 00\left(\mathrm{~F}_{3,16}=6.666, p=0.004\right), 12: 00$ $\left(\mathrm{F}_{3,16}=5.108, p=0.011\right), 15: 00\left(\mathrm{~F}_{3,16}=10.751, p<0.001\right)$, and 22:00 $\left(\mathrm{F}_{3,16}=6.003, p=0.006\right)$, except 
for values measured at 18:00 $\left(\mathrm{F}_{3,16}=2.903, p=0.067\right)$. The maximum value of $\mathrm{Pn}$ was displayed in the control at 09:00 under daylight, but Pn of yellow-poplar leaves exposed to artificial night lighting showed a greater degree of depression by $42 \%$ and $45 \%$ in T2 and T3, respectively, as compared with that of control due to a strong reduction of Gs and Tr. Despite the negative differences of Pn, Gs, and $\mathrm{Tr}$ in diurnal patterns under artificial night lighting, diurnal variations in the ratio of intercellular to ambient $\mathrm{CO}_{2}$ concentration $(\mathrm{Ci} / \mathrm{Ca})$ showed less remarkable variations after 4 and 13 months (Figures $4 \mathrm{D}$ and $5 \mathrm{D}$ ). The ratio of $\mathrm{Ci} / \mathrm{Ca}$ showed no significant differences at 12:00, 15:00, 16:00, and 22:00 among treatments. Nevertheless, the ratio of $\mathrm{Ci} / \mathrm{Ca}$ at $02: 00$ was significantly reduced by $22 \%$ and 38\% especially in $\mathrm{T} 2$ and $\mathrm{T} 3$, respectively, compared to that of control $\left(\mathrm{F}_{3,16}=36.374, p<0.001\right)$.

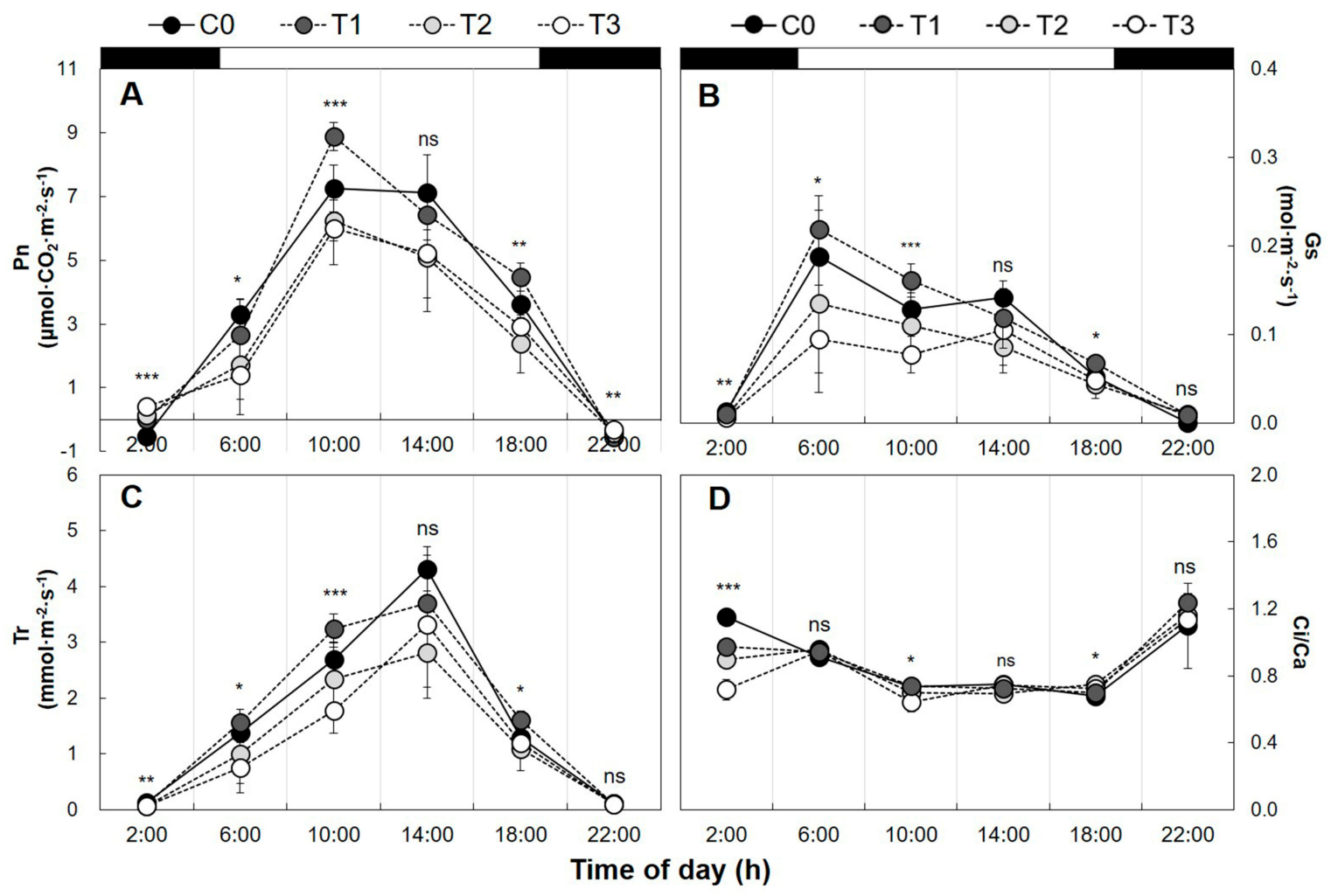

Figure 4. Diurnal patterns in leaf gas exchange parameters of yellow-poplar leaves during the 4-month treatment period. The photosynthesis during the dark period is affected by artificial night lighting. (A) Net photosynthetic rate (Pn), (B) stomatal conductance (Gs), (C) transpiration rate (Tr), and (D) ratio of intercellular $(\mathrm{Ci})$ to atmospheric $(\mathrm{Ca}) \mathrm{CO}_{2}$ concentration $(\mathrm{Ci} / \mathrm{Ca}$ ratio) of yellow-poplar plants exposed to the natural day/night cycle (C0) and the day/night with artificial lighting cycle (T1, T2, and T3). The black solid circles $(\bullet)$, gray solid circles $(\bullet)$, light gray solid circles $(\bullet)$, and hollow circles (○) represent C0, T1, T2, and T3, respectively. Black and white boxes at the top indicate the dark and light phase, respectively, in the daily cycle. The $x$-axis represents the time of day (h). Data points represent mean $\pm \mathrm{SD}(n=5)$. Asterisks represent a significant difference among treatments $\left({ }^{*} p<0.05\right.$; ** $p<0.01 ;{ }^{* * *} p<0.001 ;$ ns, not significant).

As shown in Figure 6, Pn of yellow-poplar from initial exposure on 22 April 2014 was down-regulated in the first week after the initial onset of artificial night lighting. Remarkably, the Pn showed significant differences among treatments after 1 week $\left(\mathrm{F}_{3,16}=5.168, p=0.005\right), 5$ weeks $\left(\mathrm{F}_{3,16}=6.041, p<0.005\right)$, and 8 weeks $\left(\mathrm{F}_{3,16}=27.051, p<0.001\right)$. The Pn of these plants showed significant reduction by $41 \%$ and $51 \%$ in $\mathrm{T} 2$ and $\mathrm{T} 3$, respectively, as compared to those of controls at 5 weeks after treatments (Figure 6A). Eventually, T3-type of artificial night light exposure led to the over-reduction by $28 \%$ in Pn, relative to that of control after 8 weeks. On the other hand, artificial night lighting effect on stomatal conductance (Gs) showed no statistically significant difference among 
treatments at 1, 2, and 3 weeks (Figure 6B). It was evident that there were statistically significant differences among treatments after 5 weeks $\left(\mathrm{F}_{3,16}=16.738, p<0.001\right)$, indicating a significant increase in T1 as compared to that of control. After 8 weeks from initial observation on 22 April 2014, Gs showed the statistically significant $33 \%$ reduction in $\mathrm{T} 3$ compared with that of control $\left(\mathrm{F}_{3,16}=16.313, p<0.001\right)$. Moreover, artificial night lighting caused a dramatic reduction in Tr after 5 weeks of treatment (Figure 6C).
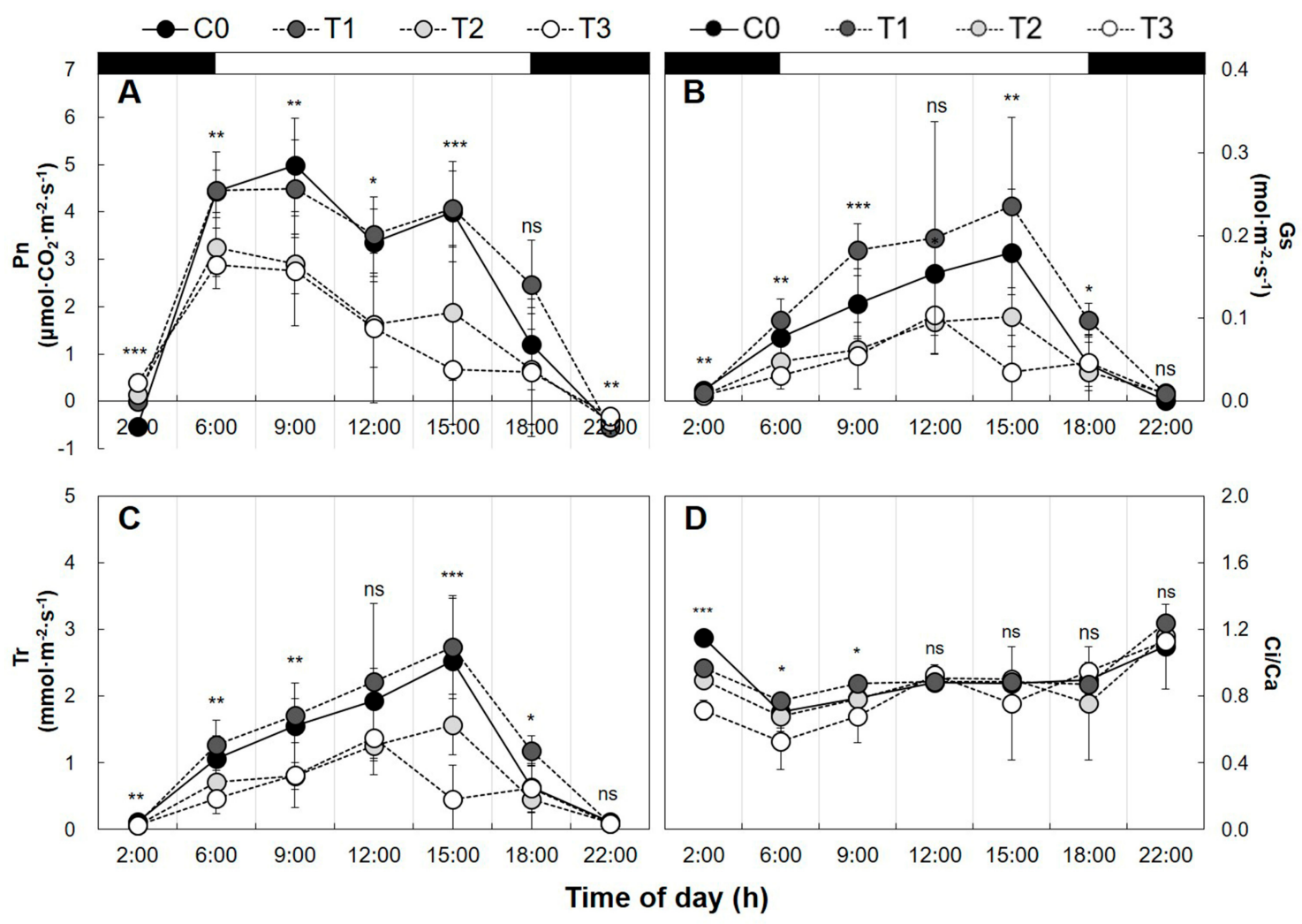

Figure 5. Diurnal patterns in leaf gas exchange parameters of yellow-poplar leaves during the 13-month treatment period. The dark period has a gas exchange rate by artificial night lighting. (A) Net photosynthetic rate (Pn), (B) stomatal conductance (Gs), (C) transpiration rate (Tr), and (D) ratio of intercellular $(\mathrm{Ci})$ to atmospheric $(\mathrm{Ca}) \mathrm{CO}_{2}$ concentration ( $\mathrm{Ci} / \mathrm{Ca}$ ratio) of yellow-poplar plants exposed to the natural day/night cycle (C0) and the day/night with artificial lighting cycle (T1, T2, and T3). The black solid circles $(\bullet)$, gray solid circles $(\bullet)$, light gray solid circles $(\bullet)$, and hollow circles $(\bigcirc)$ represent $\mathrm{C} 0, \mathrm{~T} 1, \mathrm{~T} 2$, and T3, respectively. Black and white boxes at the top indicate the dark and light phase, respectively, in the daily cycle. The $x$-axis represents the time of day (h). Data points represent mean $\pm \mathrm{SD}(n=5)$. Asterisks represent a significant difference among treatments ${ }^{*} p<0.05 ;{ }^{* *} p<0.01$; $* * * \quad p<0.001 ;$ ns, not significant).

It was evident that $\mathrm{Tr}$ indicated statistically significant differences by $48 \%$ and $55 \%$ in $\mathrm{T} 2$ and $\mathrm{T} 3$, respectively $\left(\mathrm{F}_{3,16}=6.720, p=0.003\right)$, showing no statistically significant difference in $\mathrm{T} 1$ compared with that of control. After 8 weeks, Tr showed a statistically significant decrease by $23 \%$ in T3, starting from initial observation on 22 April 2014, but showed no statistically significant difference in T1 and T2 compared with that of control. The water use efficiency (WUE) in response to artificial night lighting showed a significant decrease by $23 \%$ in T3 compared with that of control after 8 weeks $\left(\mathrm{F}_{3,16}=7.536\right.$, $p<0.001$ ), although showing no statistically significant differences among treatments at $1,2,3$, and 5 weeks (Figure 6D). 


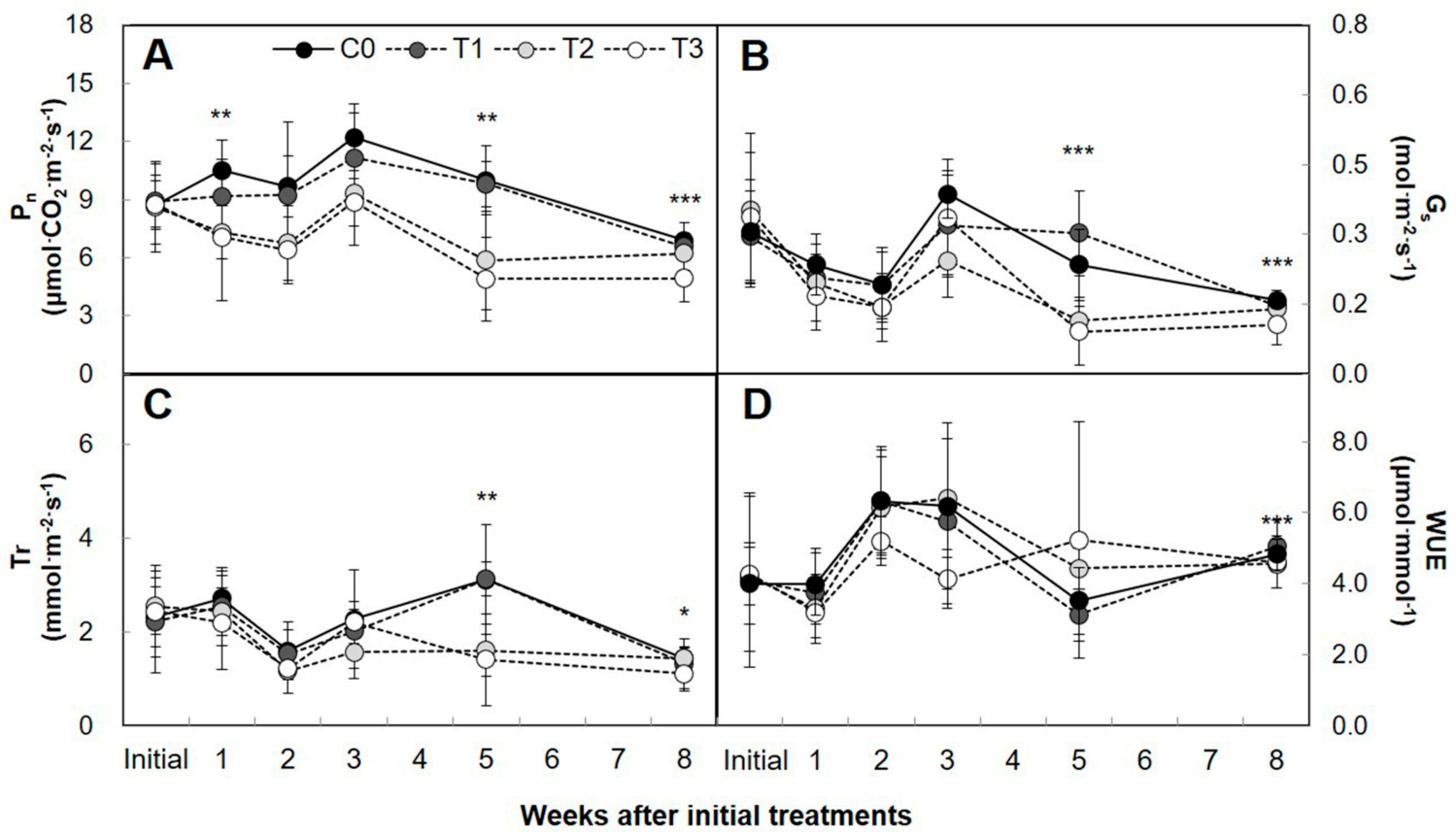

Figure 6. Seasonal patterns of leaf gas exchange parameters in yellow-poplar treated with artificial night lighting. (A) Net photosynthetic rate (Pn), (B) stomatal conductance (Gs), (C) transpiration rate (Tr), and (D) water use efficiency (WUE) of yellow-poplar plants exposed to the natural day/night cycle (C0) and the day/night with artificial lighting cycle (T1, T2, and T3) during the experimental period. The black solid circles $(\bullet)$, gray solid circles $(\bullet)$, light gray solid circles $(\bullet)$, and hollow circles ( $\bigcirc$ ) represent $\mathrm{C} 0, \mathrm{~T} 1, \mathrm{~T} 2$, and T3, respectively. The $x$-axis represents the weeks after initial onset of treatments on 22 April 2014. Data points represent mean \pm SD of five experimental replicates. Asterisks represent significant treatment effects at a single measuring date ${ }^{*} p<0.05 ;{ }^{* *} p<0.01$; ${ }^{* * *} p<$ $0.001)$.

\subsection{Oxidative Stress and Enzyme Activity}

Yellow-poplar leaves were exposed to the natural day/night cycle and the day/night with artificial lighting cycle to detect histochemical quantification of ROS, especially $\mathrm{O}_{2}{ }^{-}$and $\mathrm{H}_{2} \mathrm{O}_{2}$ after NBT and DAB staining, respectively (Figure 7). Histochemical localization of $\mathrm{O}_{2}{ }^{-}$as formation of the blue formazan was higher in T1 compared with that of $\mathrm{C} 0$ or T2 and T3 (Figure 7A). Additionally, a diffuse blue staining was evident in T1. In contrast, a granular, particulate dark blue stain was present in T2 and T3 treatments. NBT staining also showed the highest $\mathrm{O}_{2}{ }^{-}$levels in the leaves grown under $\mathrm{T} 1$ treatment. At the stained area level (Figure 7B), $\mathrm{O}_{2}{ }^{-}$level expressed as a percentage of stained spot areas to the total leaf disc areas was 39-fold higher in T2 with artificial night lighting compared with that of $\mathrm{C} 0$ without artificial night lighting $\left(\mathrm{F}_{3,16}=13.213, p<0.001\right)$. Histochemical localization of $\mathrm{H}_{2} \mathrm{O}_{2}$, as indicated by the brown compounds formed by reaction with $\mathrm{DAB}$, increased in leaf discs of T1 type-exposed plants (Figure 7A). Stained areas showed an approximately 7 times higher level in T1 than those of other treatments (Figure 7B). The stained area of $\mathrm{H}_{2} \mathrm{O}_{2}$ level showed significant increase in T1-treated plants compared to that of natural night type (C0), whereas T2 and T3 type of nighttime lighting were not statistically significant $\left(\mathrm{F}_{3,16}=10.204, p=0.001\right)$. 
(A)

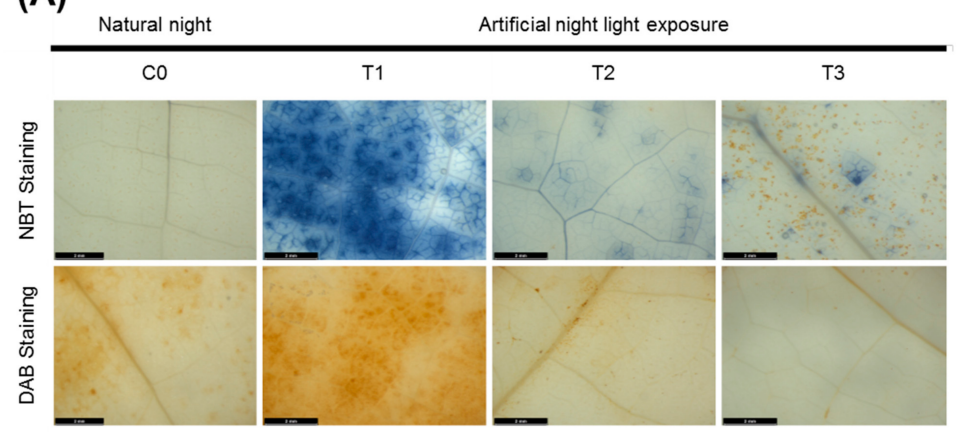

(B)

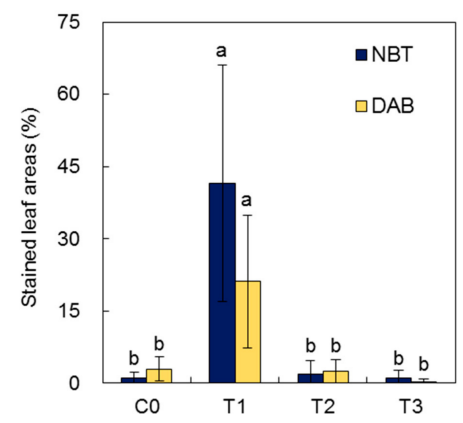

Figure 7. In situ detection of superoxide radicals $\left(\mathrm{O}_{2}{ }^{-}\right)$and hydrogen peroxide $\left(\mathrm{H}_{2} \mathrm{O}_{2}\right)$ by NBT (nitroblue tetrazolium) and DAB (3,3'-diaminobenzidine) staining, respectively, in yellow-poplar leaves exposed to artificial night light. (A) NBT and DAB staining for detecting levels of $\mathrm{O}_{2}{ }^{-}$and $\mathrm{H}_{2} \mathrm{O}_{2}$ production. Scale bar $=2 \mathrm{~mm}$. (B) NBT- and DAB-stained area in leaf discs from each treatment. Color images of leaf discs were converted to black and white images and stained leaf areas were quantified by using the software WinFOLIA Pro 2013 (WinFOLIA, Regent Instruments, Québec, Canada). Data represent the mean $\pm \mathrm{SD}(n=5)$. Different lowercase letters on the bars indicate significant differences among treatments in NBT and DAB, respectively (Tukey's test after one-way ANOVA).

SOD activity had no effects in T2 and T3 treatments exposed to artificial night lighting for two years while SOD in T3 treatment increased at the end of the experiment (Figure 8; $\mathrm{F}_{3,16}=6.452, p=0.005$ ). The SOD activity significantly increased $8 \%$ in T1 treatment treated with the lowest level of artificial night lighting, as compared with that of C0 (Figure 8). As shown in Figure 9, yellow-poplar leaves exposed to artificial night lighting showed significant improvements in MDA contents (Figure 9A; $\mathrm{F}_{3,16}=184.164, p<0.001$ ) and electrolyte leakage (Figure 9B; $\mathrm{F}_{3,16}=8.173, p=0.002$ ). The MDA contents were 2-, 3-, and 4-fold higher in T1, T2, and T3, respectively, compared with that of $\mathrm{C} 0$. The electrolyte leakage showed significant increase by $22 \%, 21 \%$, and $30 \%$ in $\mathrm{T} 1, \mathrm{~T} 2$, and T3, respectively, with artificial night light than in that without artificial night lighting.

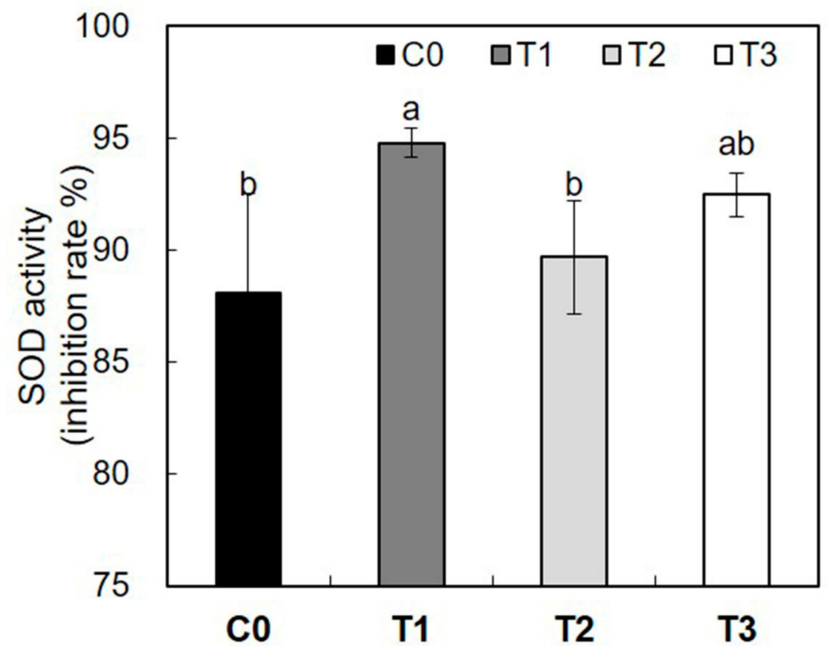

Figure 8. SOD (superoxide dismutase) activity in yellow-poplar leaves exposed to the natural day/night cycle (C0, black bar) and the day/night with artificial lighting cycle (T1, T2, and T3 denote dark gray bar, light gray bar, and white bar, respectively). Data indicate mean $\pm \operatorname{SD}(n=5)$. Different lowercase letters on the bars indicate significant differences among treatments (Tukey's test after one-way ANOVA). 

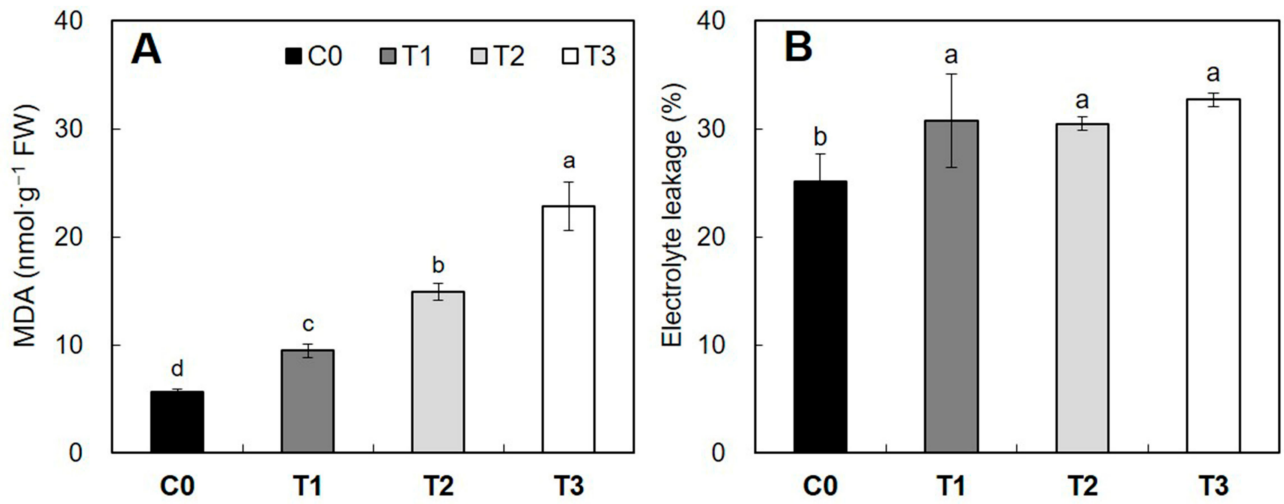

Figure 9. MDA (malondialdehyde) contents (A) and electrolyte leakage (B) in yellow-poplar leaves exposed to the natural day/night cycle ( $\mathrm{C} 0$, black bars) and the day/night with artificial lighting cycle (T1, T2, and T3 denote dark gray bars, light gray bars, and white bars, respectively). Data indicate mean $\pm \mathrm{SD}(n=5)$. Different lowercase letters on the bars indicate significant differences among treatments (Tukey's test after one-way ANOVA).

\subsection{Water Relations and Plant Growth}

Artificial night lighting had no effects on relative water content (RWC) in T1 and T2 treatments after exposure to artificial night lighting for two years while RWC in T3 treatment decreased at the end of the experiment (Figure 10; F3,8 $=14.323, p<0.001$ ). When compared to control (C0), RWC significantly decreased by $8 \%$ in T3 treated with the highest level of artificial night lighting.

To explore potential effects of artificial night lighting on aboveground (Figure 11) and belowground plant biomass (Figure 12) of yellow-poplar seedlings, plants were harvested for fresh and dry weight both aboveground and belowground at the end of the 3-year experiment. As shown in Figures 11 and 12, artificial night lighting led to a significant reduction in aboveground and belowground biomass, as compared with those of control without artificial night lighting. In aboveground plant biomass, fresh and dry weight was significantly affected by artificial night HPS lighting during the night (Figure 11). Under artificial night lighting, aboveground fresh weight was significantly decreased by $22 \%, 18 \%$, and $27 \%$ in $\mathrm{T} 1, \mathrm{~T} 2$, and $\mathrm{T} 3$, respectively, relative to that of control (Figure $11 \mathrm{~A} ; \mathrm{F}_{3,16}=7.424, p=0.002$ ). Similarly, dry weight showed significant decrease by $44 \%, 39 \%$, and $46 \%$ in T1, T2, and T3, respectively, with artificial night lighting than in that of control (Figure 11B; $\mathrm{F}_{3,16}=70.581, p<0.001$ ).

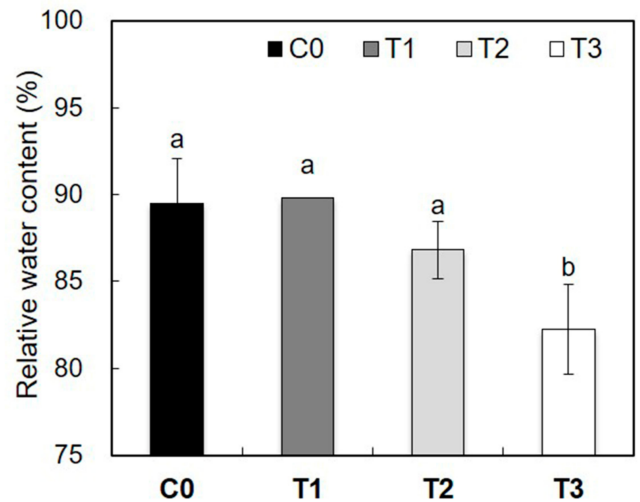

Figure 10. Relative water contents (RWC) in yellow-poplar leaves exposed to the natural day/night cycle (C0, black bar) and the day / night with artificial lighting cycle (T1, T2, and T3 denote dark gray bar, light gray bar, and white bar, respectively). Data indicate mean $\pm \mathrm{SD}(n=5)$. Different lowercase letters on the bars indicate significant differences among treatments (Tukey's test after one-way ANOVA). 

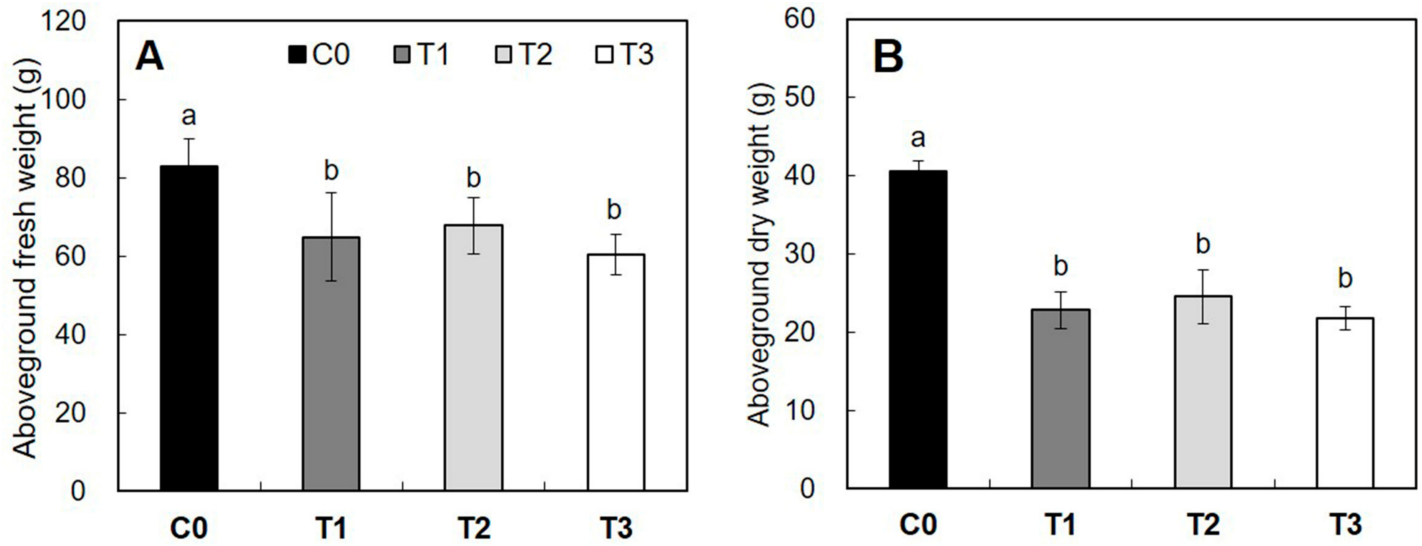

Figure 11. Aboveground fresh and dry weight in yellow-poplar exposed to artificial night lighting. (A) Fresh weight and (B) dry weight in yellow-poplar exposed to the natural day/night cycle (C0, black bars) and the day/night with artificial lighting cycle (T1, T2, and T3 denote dark gray bars, light gray bars, and white bars, respectively). Data indicate mean $\pm \operatorname{SD}(n=5)$. Different lowercase letters on the bars indicate significant differences among treatments (Tukey's test after one-way ANOVA).

A similar trend was observed in belowground biomass of yellow-poplar seedlings after artificial night lighting (Figure 12). In an analysis of belowground biomass, a significant decrease of fresh and dry weight was noted in artificial night lighting with the HPS lamp. The belowground fresh weight was remarkably decreased by $50 \%, 56 \%$, and $48 \%$ in T1, T2, and T3 compared with that of C0 (Figure 12; $\left.\mathrm{F}_{3,16}=36.248, p<0.001\right)$. Furthermore, the belowground dry weight was significantly decreased by $56 \%, 55 \%$, and $46 \%$ in T1, T2, and T3 compared with that of $\mathrm{C} 0$ (Figure 12B; $\mathrm{F}_{3,16}=27.157, p<0.001$ ).
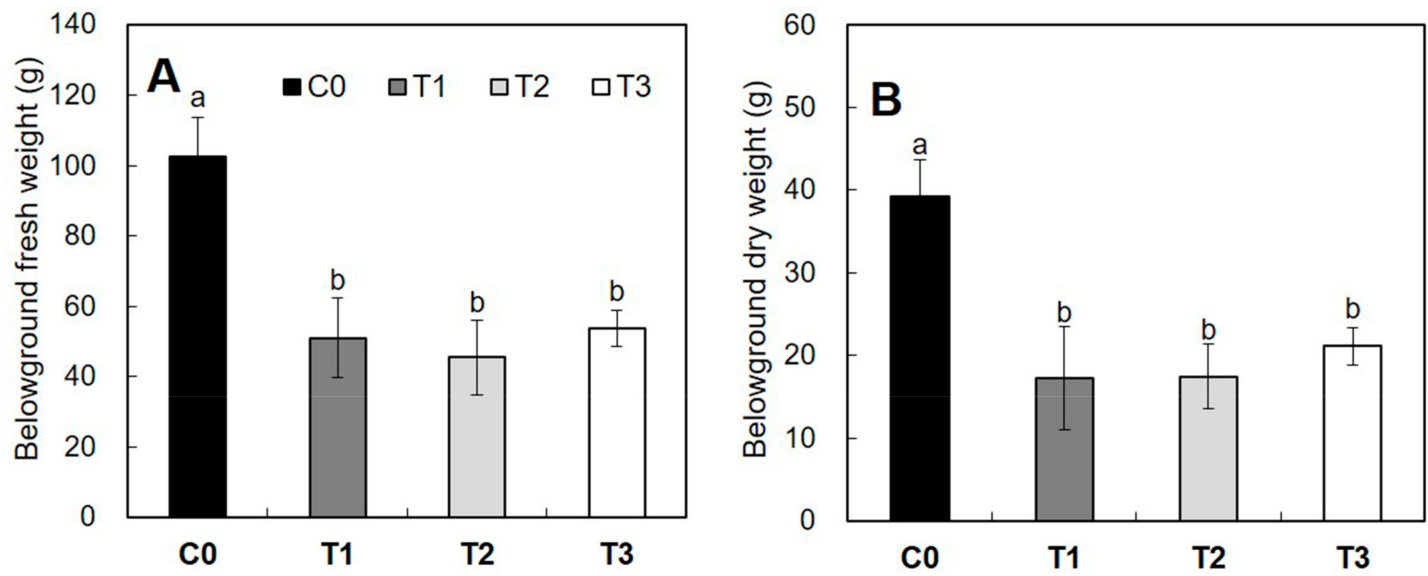

Figure 12. Belowground fresh and dry weight in yellow-poplar exposed to artificial night lighting. (A) Fresh weight and (B) dry weight in yellow-poplar exposed to the natural day/night cycle (C0, black bars) and the day/night with artificial lighting cycle (T1, T2, and T3 denote dark gray bars, light gray bars, and white bars, respectively). Data indicate mean $\pm \operatorname{SD}(n=5)$. Different lowercase letters on the bars indicate significant differences among treatments (Tukey's test after one-way ANOVA).

\section{Discussion}

Over the past 100 years, for example, the nighttime light pollution caused by excessive amounts and indiscriminate diffusion of external lighting has emerged as an important environmental issue because of its adverse effects [2-5]. To elucidate how repetitive exposure to artificial night lighting affects photosynthetic pigments as a potential indicator of premature leaf senescence as well as yellowing and defoliation in newly initiated leaves, yellow-poplar seedlings were exposed to the 
natural day/night cycle and the day/night with artificial lighting cycle. The most obvious difference in response to artificial night lighting was a significant loss of green coloration of night light-exposed leaves compared to controls, possibly as a result of chlorophyll degradation in response to the treatment (Figure 1).

Consistent with the above chlorophyll results, newly initiated leaf symptoms of plants exposed to artificial night lighting resulted in premature senescence of leaves as well as quick yellowing, defoliation, and tip burn. During the appearance of premature senescence, chlorophyll degradation promotes an accelerated leaf yellowing in Arabidopsis thaliana (L.) Heynh. [20,39], Nicotiana tabacum L. [40], and Dunaliella salina Teod. [41]. As shown in Figure 1, these data indicate that there were significant differences in pigment concentrations throughout three months post-treatment and one year follow-up assessment. In this study, chlorophyll and carotenoid contents were sensitive to enhanced artificial night lighting levels and treatment duration. Interestingly, important changes are observed for chlorophyll $b$ contents under the day/night with artificial lighting cycle during one year follow-up assessment. In levels of artificial night lighting, there was a 0.68 to 2.23 times higher level of chlorophyll $b$ contents, which resulted in over $65 \%$ reduction in the $\mathrm{Chl}_{\mathrm{a}} / \mathrm{Ch}_{\mathrm{b}}$ ratio.

Higher plants display the ability to regulate acclimation responses under different environmental light conditions through the regulation of the light-harvesting photosystem II (PSII) antenna size [42,43]. Nakagawara et al. [44] discovered that the step of converting chlorophyll $a$ to chlorophyll $b$ involves sensing the level of chlorophyll $b$. Yamasato et al. [45] had previously demonstrated that this regulatory mechanism in the PSII antenna size through the regulation of chlorophyll $b$ synthesis by chlorophyllide $a$ oxygenase $(\mathrm{CAO})$ contributes to the protective strategy in photosynthesis and protection under photo-oxidative stress. Furthermore, the PSII antenna size is determined by the amount of the light-harvesting chlorophyll $a / b$-protein complex of PSII (LHCII) associated with photosystem II core complexes [46]. Elevated levels of chlorophyll $b$ are mediated via enhanced $C A O$ and $L h c b 1^{*} 1$ (the gene encoding the Light-harvesting Chlorophyll $a / b$ binding protein 2, also called CAB2) gene expression $[40,41,47]$. Excess light energy induces photoinhibition, but an insufficient supply of light energy leads to the growth retardation in plants. In the course of light stress responses, chlorophyll $b$ synthesis must be dynamically regulated in response to changes in light availability [44]. As a consequence of PSII antenna size adjustments from the present study, the $\mathrm{Chl}_{\mathrm{a}} / \mathrm{Chl}_{\mathrm{b}}$ ratio decreases in yellow-poplar grown under artificial night lighting (Figure 1), thus contributing to the enlargement of the PSII antenna size [38,40]. Therefore, these enhanced chlorophyll $b$ contents, as accessory pigments, may serve as light harvesting or to the dissipation of excitation energy (photoprotection) under artificial night lighting.

Chlorophyll fluorescence transients as nondestructive determination of PSII photochemistry were employed to elucidate the temporal dynamics of photosynthesis and growth regulated by artificial night lighting (Figure 2). The PSII as the heart of the photosynthetic process is highly sensitive to the environmental stresses. Its activity could be determined with one non-invasive time-resolved fluorescence measurement, which could measure the polyphasic rise with the basic steps of OJIP [43,48-54]. Several studies have shown that the chlorophyll $a$ transient has become one of the most popular tools to estimate stress-induced changes in photosynthetic performance. For example, the shape of the OJIP transient seems to be particularly sensitive to environmental stresses, such as drought [55], salt stress [56], high temperature [57], and heat stress [58]. The chlorophyll fluorescence parameter $\mathrm{Fv} / \mathrm{Fm}$ has been used as an indicator of physiological stress. The experimental evidence has shown that $\mathrm{Fv} / \mathrm{Fm}$ is often insensitive to stress and is not always a suitable parameter for screening stress tolerance [33,56]. Nonetheless, Fv/Fm reflects the maximum quantum efficiency of PSII photochemistry and has been widely used for early stress detection in plants [59]. The low Fv/Fm is consistent with the poor recovery of PSII. Therefore, the highest level of artificial night lighting may substantially reduce the energy cost. In addition, the reaction centers of PSII were remarkably damaged by artificial night lighting, which was reflected by a decrease in the maximum quantum yield of PSII (Figure 3B) and the density of $\mathrm{O}_{\mathrm{A}}{ }^{-}$reducing PSII reaction centers (RC) per cross section (CS). 
The OJIP transients containing abundant information about the primary photochemical reactions of PSII, have been widely used in PSII activity studies. In addition, $\mathrm{PI}_{\mathrm{ABS}}$, as the most sensitive parameter of OJIP transients to various stress treatments [58], combines the responses caused by the photochemical and non-photochemical properties as well as the density of active reaction centers per chlorophyll absorption [35]. The increases at the K step of the OJIP transients (at $300 \mu \mathrm{s}$ ) are also widely used as specific indicators of damage to the donor side of PSII [47]. The peak at J step (at $2 \mathrm{~ms}$ ) indicates that the PSII acceptor side is inhibited. More specifically, the electron moves beyond $\mathrm{O}_{\mathrm{A}}{ }^{-}$is limited [60]. Artificial night lighting significantly damaged the donor side of PSII, which was indicated by significant increase of the $\mathrm{K}$ step in the OJIP transients and the relative variable fluorescence at the K step (Figure 2). Specifically, the peak of the K-step under stress is an effective injury indicator relative to the inactivation of the oxygen-evolving complex (OEC) to the donor side of PSII $[32,57,60]$. The dramatic inhibition of the $\mathrm{O}_{2}$ evolution capacity of leaves exposed to artificial night lighting suggested that the donor side of PSII was damaged during artificial night lighting. Artificial night lighting also inhibited the acceptor side of PSII, which was shown by an increase of the $\mathrm{J}$ steps in the OJIP transients (Figure 2) and a decline in the efficiency of electron moves beyond $\mathrm{Q}_{\mathrm{A}}$. The above results indicate that the activities of the donor and acceptor sides and reaction center were inhibited during artificial night lighting. PSII photoinhibition is a result of the imbalance between PSII photodamage and the repair of photodamaged PSII [48]. Therefore, artificial night lighting displays photoinhibition-like damage to the photosynthetic apparatus in yellow-poplar leaves.

Diurnal variations in the capacity and efficiency of carbon fixation are characteristics of plants grown under the natural environment. A general consensus, however, is that carbon fixation is derived from complex metabolic feedbacks and endogenous circadian rhythms but is not passively regulated by the availability of light [61]. Leaf Pn showed a bimodal pattern and the midday depression in Pn was observed at 13:00. Depression in Pn at midday was mostly attributed to $\mathrm{L}_{S}$ since the reduction in Pn was followed by the significant reduction in Gs (Figures 4 and 5). Several studies have shown that circadian clocks synchronize various physiological, metabolic and developmental processes of organisms with specific phases of recurring changes in their environment (e.g., day and night or seasons). Circadian clock synchronization to daily cyclic environmental signals temporally regulates many aspects of plant growth and development [62], and is crucial for plant fitness, adaptation, and survival [63]. Although the photosynthetic capacity triggered by artificial night lighting is well-documented [25,51], the dynamics of the day/night with artificial lighting cycle need further studies. The increase in photosynthetic rates under continuous light was well reflected by the observed trends [11]. The sensitivity of photosynthetic rates in response to continuous night light has also been shown by Velez-Ramirez et al. [14].

It is known that $\mathrm{O}_{2}{ }^{-}$and $\mathrm{H}_{2} \mathrm{O}_{2}$ can be generated by the reduction of $\mathrm{O}_{2}$ in photosynthetic electron transfer reactions. $\mathrm{O}_{2}$ can act as a terminal acceptor in the so-called pseudo-cyclic electron transport or Mehler reaction at the acceptor side of PSI [64]. The production of $\mathrm{O}_{2}{ }^{-}$can be detected using the dye NBT, forming dark blue insoluble formazan produced by the reaction of NBT. Histochemical staining for reactive oxidative species (ROS) production in leaf tissues has been used to identify sites of photo-oxidative stress responses in excess light [65], fluctuating light [66], enhanced ultraviolet-B radiation [67], and photoinhibitory illumination [68] as well as cadmium-treated stress [69] and water stress [70]. In-situ formation of $\mathrm{H}_{2} \mathrm{O}_{2}$ can be visualized as reddish-brown coloration by forming perhydroxides precipitate or brown DAB- $\mathrm{H}_{2} \mathrm{O}_{2}$ polymer [71,72]. Therefore, the $\mathrm{H}_{2} \mathrm{O}_{2}$ production in C0-type, T1-type, T2-type, and T3-type leaves was measured by the histochemical staining assay with DAB (Figure 7). Continuous light can induce a higher activity of antioxidative enzymes due to a higher production of ROS $[73,74]$. Since plants grown under continuous light results in a hyper-accumulation of carbohydrates, leading to an over-reduction of electron acceptors, the abundant supply of assimilates, in turn, cause an oxidative damage due to the electron-donating to $\mathrm{O}_{2}$ generating ROS [14]. The present study reveals that the day/night with artificial lighting cycle resulted in the significant accumulation of $\mathrm{H}_{2} \mathrm{O}_{2}$ and $\mathrm{O}_{2}{ }^{-}$within leaves during premature leaf senescence and leaf tissue necrosis (Figure 7). 
From the quantitative analysis of ROS generation, artificial night light-induced ROS burst is prior to membrane damage, which is earlier compared with the appearance of evident physiological damage attributed to turgor loss and tissue collapse. PSII photoinhibitory damage can result in the formation of a complex array of ROS in chloroplasts $[23,24,75]$. The results from histochemical staining (Figure 7A) showed that $\mathrm{T} 1$ type of the day/night with artificial lighting cycle caused the generation of large amounts of $\mathrm{H}_{2} \mathrm{O}_{2}$ and $\mathrm{O}_{2}{ }^{-}$in chloroplasts because these dyes, including DAB and NBT are specific molecules used to indicate $\mathrm{H}_{2} \mathrm{O}_{2}$ and $\mathrm{O}_{2}{ }^{-}$. It is suggested that the reduction of $\mathrm{O}_{2}$ is the starting point for a series of reactions leading to ROS generation on the PSII electron acceptor side [76]. The ROS as a product of normal metabolism can provide beneficial or detrimental effects to plant cells and tissues [77-81].

At low level of ROS generation, ROS is predominantly beneficial to cells, supporting as redox messengers in intracellular signaling and regulation for cellular processes and viability [77]. On the one hand, enhanced ROS accumulation during environmental stresses can be generated inside chloroplasts as by-products of photosynthesis [21]. Moreover, the enhanced levels of ROS under abiotic stress conditions can induce oxidative damage to plant cell by causing lipid peroxidation, protein damage, membrane destruction, and damage to nuclei, ultimately leading to a deliberate activation of the cell death pathway such as ferroptosis or regulated necrosis [73]. As shown in Figure 9, yellow-poplar leaves exposed to artificial night lighting showed significant improvements in malondialdehyde and electrolyte leakage as indicators of lipid peroxidation and membrane permeability, respectively. Therefore, enhanced production of ROS generated as a by-product of photosynthesis can be expected in T1 plants (Figures 4 and 5). A direct result of these primary effects is enhanced accumulation of ROS that triggers a series of harmful processes to plant cells at low level of artificial night lighting (Figure 7). In general, light intensity decreases rapidly with distance from the focal point of the light source. Tree leaves adjacent to street lights or car headlights can be exposed to about $5000 \mathrm{~L} \times\left(60 \mu \mathrm{mol} \cdot \mathrm{m}^{-2} \cdot \mathrm{s}^{-1}\right)$ at the upper end of the scale, while typical stable ground level illuminance (i.e., directly beneath street lights) of roadside vegetation are around $50 \mathrm{~lx}\left(0.6 \mu \mathrm{mol} \cdot \mathrm{m}^{-2} \cdot \mathrm{s}^{-1}\right)$ [82]. Photosynthesis of plants exposed to artificial lighting at night can be limited by the low quantum flux densities of nighttime light compared with that of daylight. Theoretically, urban skyglow can be sufficient to cause a downregulation of photosynthesis [83]. In addition, leaves close to streetlights, such as those in the tree canopy, may limit their carbon fixation [82].

As a result, this disruptive process deviates electrons from the PSI acceptor side to reduce $\mathrm{O}_{2}$ generating $\mathrm{O}_{2}{ }^{-}$and $\mathrm{H}_{2} \mathrm{O}_{2}$. Therefore, leaves of $\mathrm{T} 2$ and $\mathrm{T} 3$ plants exposed to artificial night lighting show lower levels of oxidative stress, as compared to that in T1. These results suggest that ROS burst might also play an important role in subsequent defense responses of artificial night lighting-triggered cell senescence and leaf tissue necrosis. Artificial night lighting can lead to the formation of $\mathrm{H}_{2} \mathrm{O}_{2}$ and $\mathrm{O}_{2}{ }^{-}$in chloroplasts under the lowest level of artificial night lighting due to interruption of PSI and PSII. Therefore, their primary toxic mechanism can mediate to block the synthesis of ATP (adenosine-5'-triphosphate) and NADPH (nicotinamide adenine dinucleotide phosphate), being followed by ROS generation, oxidative damage and cell death. Depending on the experimental conditions, different ROS sources might be important for the initiation and acceleration of senescence. Therefore, these oxidative damages result in the reduction of aboveground and belowground plant biomass under the night with artificial lighting cycle, as compared with natural night (Figures 11 and 12).

\section{Conclusions}

The study presents several new and interesting physio-biochemical findings that will help us to understand the impacts of light pollution in plants. Particularly, these findings point to the following major highlights. Nighttime artificial HPS lighting acts as a depressor of the fitness of photosynthesis and growth patterns, via a modification of the photosynthetic light harvesting apparatus. Moreover, artificial night lighting leads to the enhanced accessory pigments, the reduced photosystem II photochemistry, increased 
stomatal limitation, downregulation of photosynthesis, and decreased aboveground and belowground plant biomass in artificial night lighting. Markedly, the chronic exposure to artificial night lighting can dramatically influence the physiological and biochemical changes of seedlings, especially the circadian disruption between dusk and dawn. This study provides potential new applications for further studies investigating the matching of endogenous rhythms to environmental rhythms and the effect on plant growth and fitness, leading to better understanding of the dynamic kinetics of plant growth, photosynthetic process, and overall productivity. Henceforward, future studies should be evaluated to understand eco-physiological impacts of nighttime artificial lighting in urban environments and interactions with other photochemical pollutants so that effective pollution prevention practices can be developed.

Acknowledgments: This study was carried out with the support of 'R\&D Program for Forest Science Technology (Project No. 2017047B10-1818-BB01)' provided by Korea Forest Service (Korea Forestry Promotion Institute).

Author Contributions: Myeong Ja Kwak and Su Young Woo conceived and designed the experiments; Myeong Ja Kwak, Sun Mi Je, and Taeyoon Lee performed the experiments; Myeong Ja Kwak, Sun Mi Je, Hyo Cheng Cheng, Se Myeong Seo, Jeong Ho Park, Saeng Geul Baek, Inkyin Khaine, Taeyoon Lee, Jihwi Jang, Yang Li, Haenaem Kim, Jong Kyu Lee, and Jieun Kim analyzed the data; Su Young Woo contributed reagents/materials/analysis tools; Myeong Ja Kwak and Su Young Woo wrote the paper.

Conflicts of Interest: The authors declare no conflict of interest.

\section{References}

1. Navara, K.J.; Nelson, R.J. The dark side of light at night: Physiological, epidemiological, and ecological consequences. J. Pineal Res. 2007, 43, 215-224. [CrossRef] [PubMed]

2. Chepesiuk, R. Missing the dark: Health effects of light pollution. Environ. Health Perspect. 2009, 117, A20-A27. [CrossRef] [PubMed]

3. Gaston, K.J.; Bennie, J.; Davies, T.W.; Hopkins, J. The ecological impacts of nighttime light pollution: A mechanistic appraisal. Biol. Rev. 2013, 88, 912-927. [CrossRef] [PubMed]

4. Fonken, L.K.; Nelson, R.J. The effects of light at night on circadian clocks and metabolism. Endocr. Rev. 2014, 35, 648-670. [CrossRef] [PubMed]

5. Da Silva, A.; Valcu, M.; Kempenaers, B. Light pollution alters the phenology of dawn and dusk singing in common European songbirds. Philos. Trans. R. Soc. B 2015, 370, 20140126. [CrossRef] [PubMed]

6. Hölker, F.; Moss, T.; Griefahn, B.; Kloas, W.; Voigt, C.C.; Henckel, D.; Hänel, A.; Kappeler, P.M.; Völker, S.; Schwope, A.; et al. The dark side of light: A transdisciplinary research agenda for light pollution policy. Ecol. Soc. 2010, 15, 13. [CrossRef]

7. Bazzaz, F.A.; Miao, S.L. Successional status, seed size, and responses of tree seedlings to $\mathrm{CO}_{2}$, light, and nutrients. Ecology 1993, 74, 104-112. [CrossRef]

8. Hättenschwiler, S.; Miglietta, F.; Raschi, A.; Körner, C. Thirty years of in situ tree growth under elevated $\mathrm{CO}_{2}$ : A model for future forest responses? Glob. Chang. Biol. 1997, 3, 463-471. [CrossRef]

9. Kangasjärvi, S.; Neukermans, J.; Li, S.; Aro, E.M.; Noctor, G. Photosynthesis, photorespiration, and light signalling in defence responses. J. Exp. Bot. 2012, 63, 1619-1636. [CrossRef] [PubMed]

10. Stitt, M.; Zeeman, S.C. Starch turnover: Pathways, regulation and role in growth. Curr. Opin. Plant Biol. 2012, 15, 282-292. [CrossRef] [PubMed]

11. Pilkington, S.M.; Encke, B.; Krohn, N.; Hoehne, M.; Stitt, M.; Pyl, E.T. Relationship between starch degradation and carbon demand for maintenance and growth in Arabidopsis thaliana in different irradiance and temperature regimes. Plant Cell Environ. 2015, 38, 157-171. [CrossRef] [PubMed]

12. Ksas, B.; Becuwe, N.; Chevalier, A.; Havaux, M. Plant tolerance to excess light energy and photo-oxidative damage relies on plastoquinone biosynthesis. Sci. Rep. 2015, 5, 10919. [CrossRef] [PubMed]

13. Tang, Y.; Fu, X.; Shen, Q.; Tang, K. Roles of MPBQ-MT in promoting $\alpha / \gamma$-tocopherol production and photosynthesis under high light in Lettuce. PLoS ONE 2016, 11, e0148490. [CrossRef] [PubMed]

14. Velez-Ramirez, A.I.; van Ieperen, W.; Vreugdenhil, D.; Millenaar, F.F. Plants under continuous light. Trends Plant Sci. 2011, 16, 310-318. [CrossRef] [PubMed] 
15. Dorais, M.; Yelle, S.; Gosselin, A. Influence of extended photoperiod on photosynthate partitioning and export in tomato and pepper plants. N. Z. J. Crop Hortic. Sci. 1996, 24, 29-37. [CrossRef]

16. Cushman, K.E.; Tibbitts, T.W. The role of ethylene in the development of constant-light injury of potato and tomato. J. Am. Soc. Hortic. Sci. 1998, 123, 239-245. [PubMed]

17. Demers, D.A.; Dorais, M.; Wien, C.H.; Gosselin, A. Effects of supplemental light duration on greenhouse tomato (Lycopersicon esculentum Mill.) plants and fruit yields. Sci. Hortic. 1998, 74, 295-306. [CrossRef]

18. Van Gestel, N.C.; Nesbit, A.D.; Gordon, E.P.; Green, C.; Paré, P.W.; Thompson, L.; Peffley, E.B.; Tissue, D.T. Continuous light may induce photosynthetic downregulation in onion-consequences for growth and biomass partitioning. Physiol. Plant. 2005, 125, 235-246. [CrossRef]

19. Lim, P.O.; Kim, H.J.; Nam, H.G. Leaf senescence. Annu. Rev. Plant Biol. 2007, 58, 115-136. [CrossRef] [PubMed]

20. Wang, J.; Leister, D.; Bolle, C. Photosynthetic lesions can trigger accelerated senescence in Arabidopsis thaliana. J. Exp. Bot. 2015, 66, 6891-6903. [CrossRef] [PubMed]

21. Apel, K.; Hirt, H. Reactive oxygen species: Metabolism, oxidative stress, and signal transduction. Annu. Rev. Plant Biol. 2004, 55, 373-399. [CrossRef] [PubMed]

22. Asada, K. Production and scavenging of reactive oxygen species in chloroplasts and their functions. Plant Physiol. 2006, 141, 391-396. [CrossRef] [PubMed]

23. Laloi, C.; Apel, K.; Danon, A. Reactive oxygen signalling: The latest news. Curr. Opin. Plant Biol. 2004, 7, 323-328. [CrossRef] [PubMed]

24. Förster, B.; Osmond, C.B.; Pogson, B.J. Improved survival of very high light and oxidative stress is conferred by spontaneous gain-of-function mutations in Chlamydomonas. Biochim. Biophys. Acta 2005, 1709, 45-57. [CrossRef] [PubMed]

25. Tewolde, F.T.; Lu, N.; Shiina, K.; Maruo, T.; Takagaki, M.; Kozai, T.; Yamori, W. Nighttime supplemental LED inter-lighting improves growth and yield of single-truss tomatoes by enhancing photosynthesis in both winter and summer. Front. Plant Sci. 2016, 7, 448. [CrossRef] [PubMed]

26. Xu, D.Q.; Chen, Y.; Chen, G.Y. Light-harvesting regulation from leaf to molecule with the emphasis on rapid changes in antenna size. Photosynth. Res. 2015, 124, 137-158. [CrossRef] [PubMed]

27. Higa, T.; Wada, M. Chloroplast avoidance movement is not functional in plants grown under strong sunlight. Plant Cell Environ. 2016, 39, 871-882. [CrossRef] [PubMed]

28. Elvidge, C.D.; Keith, D.M.; Tuttle, B.T.; Baugh, K.E. Spectral identification of lighting type and character. Sensors 2010, 10, 3961-3988. [CrossRef] [PubMed]

29. Croce, R.; Van Amerongen, H. Natural strategies for photosynthetic light harvesting. Nat. Chem. Biol. 2014, 10, 492-501. [CrossRef] [PubMed]

30. Kwak, M.J.; Lee, S.H.; Khaine, I.; Je, S.M.; Lee, T.Y.; You, H.N.; Lee, H.K.; Jang, J.H.; Kim, I.R.; Woo, S.Y. Stomatal movements depend on interactions between external night light cue and internal signals activated by rhythmic starch turnover and abscisic acid (ABA) levels at dawn and dusk. Acta Physiol. Plant. 2017, 39, 162. [CrossRef]

31. Arnon, D.I. Copper enzymes in isolated chloroplasts. Polyphenoloxidase in Beta vulgaris. Plant Physiol. 1949, 24, 1-15. [CrossRef] [PubMed]

32. Strasser, R.J.; Tsimilli-Michael, M.; Srivastava, A. Analysis of the Chlorophyll $a$ Fluorescence Transient. In Chlorophyll a fluorescence: A Signature of Photosynthesis; Papageorgiou, G.C., Govindjee, Eds.; Advances in Photosynthesis and Respiration Vol. 19; Springer: Dordrecht, The Netherlands, 2004; pp. 321-362, ISBN 978-1-4020-3218-9.

33. Strauss, A.J.; Krüger, G.H.J.; Strasser, R.J.; Van Heerden, P.D.R. Ranking of dark chilling tolerance in soybean genotypes probed by the chlorophyll $a$ fluorescence transient OJIP. Environ. Exp. Bot. 2006, 56, 147-157. [CrossRef]

34. Kwak, M.J.; Lee, S.H.; Woo, S.Y. Physiological and biochemical traits of different water and light intensities on cork oak (Quercus suber L.) seedlings. Afr. J. Biotechnol. 2011, 10, 15305-15319. [CrossRef]

35. Dutilleul, C.; Garmier, M.; Noctor, G.; Mathieu, C.; Chétrit, P.; Foyer, C.H.; De Paepe, R. Leaf mitochondria modulate whole cell redox homeostasis, set antioxidant capacity, and determine stress resistance through altered signaling and diurnal regulation. Plant Cell 2003, 15, 1212-1226. [CrossRef] [PubMed]

36. Lin, Z.F.; Liu, N.; Lin, G.Z.; Peng, C.L. In situ localisation of superoxide generated in leaves of Alocasia macrorrhiza (L.) Shott under various stresses. J. Plant Biol. 2009, 52, 340-347. [CrossRef] 
37. Daudi, A.; Cheng, Z.; O’Brien, J.A.; Mammarella, N.; Khan, S.; Ausubel, F.M.; Bolwell, G.P. The apoplastic oxidative burst peroxidase in Arabidopsis is a major component of pattern-triggered immunity. Plant Cell 2012, 24, 275-287. [CrossRef] [PubMed]

38. Nishiyama, R.; Watanabe, Y.; Fujita, Y.; Le, D.T.; Kojima, M.; Werner, T.; Vankova, R.; Yamaguchi-Shinozaki, K.; Shinozaki, K.; Kakimoto, T.; et al. Analysis of cytokinin mutants and regulation of cytokinin metabolic genes reveals important regulatory roles of cytokinins in drought, salt and abscisic acid responses, and abscisic acid biosynthesis. Plant Cell 2011, 23, 2169-2183. [CrossRef] [PubMed]

39. Song, Y.; Xiang, F.; Zhang, G.; Miao, Y.; Miao, C.; Song, C.P. Abscisic acid as an internal integrator of multiple physiological processes modulates leaf senescence onset in Arabidopsis thaliana. Front. Plant Sci. 2016, 7, 181. [CrossRef] [PubMed]

40. Pattanayak, G.K.; Biswal, A.K.; Reddy, V.S.; Tripathy, B.C. Light-dependent regulation of chlorophyll b biosynthesis in chlorophyllide a oxygenase overexpressing tobacco plants. Biochem. Biophys. Res. Commun. 2005, 326, 466-471. [CrossRef] [PubMed]

41. Masuda, T.; Tanaka, A.; Melis, A. Chlorophyll antenna size adjustments by irradiance in Dunaliella salina involve coordinate regulation of chlorophyll $a$ oxygenase $(C A O)$ and Lhcb gene expression. Plant Mol. Biol. 2003, 51, 757-771. [CrossRef] [PubMed]

42. Borisova-Mubarakshina, M.M.; Ivanov, B.N.; Vetoshkina, D.V.; Lubimov, V.Y.; Fedorchuk, T.P.; Naydov, I.A.; Kozuleva, M.A.; Rudenko, N.N.; Dall'Osto, L.; Cazzaniga, S.; et al. Long-term acclimatory response to excess excitation energy: Evidence for a role of hydrogen peroxide in the regulation of photosystem II antenna size. J. Exp. Bot. 2015, 66, 7151-7164. [CrossRef] [PubMed]

43. Bielczynski, L.W.; Schansker, G.; Croce, R. Effect of light acclimation on the organization of photosystem II super- and sub-complexes in Arabidopsis thaliana. Front. Plant Sci. 2016, 7, 105. [CrossRef] [PubMed]

44. Nakagawara, E.; Sakuraba, Y.; Yamasato, A.; Tanaka, R.; Tanaka, A. Clp protease controls chlorophyll b synthesis by regulating the level of chlorophyllide a oxygenase. Plant J. 2007, 49, 800-809. [CrossRef] [PubMed]

45. Yamasato, A.; Nagata, N.; Tanaka, R.; Tanaka, A. The N-terminal domain of chlorophyllide a oxygenase confers protein instability in response to chlorophyll b accumulation in Arabidopsis. Plant Cell 2005, 17, 1585-1597. [CrossRef] [PubMed]

46. Bailey, S.; Walters, R.G.; Jansson, S.; Horton, P. Acclimation of Arabidopsis thaliana to the light environment: The existence of separate low light and high light responses. Planta 2001, 213, 794-801. [CrossRef] [PubMed]

47. Tanaka, A.; Ito, H.; Tanaka, R.; Tanaka, N.K.; Yoshida, K.; Okada, K. Chlorophyll a oxygenase (CAO) is involved in chlorophyll $b$ formation from chlorophyll a. Proc. Natl. Acad. Sci. USA 1998, 95, 12719-12723. [CrossRef] [PubMed]

48. Murata, N.; Takahashi, S.; Nishiyama, Y.; Allakhverdiev, S.I. Photoinhibition of photosystem II under environmental stress. Biochim. Biophys. Acta 2007, 1767, 414-421. [CrossRef] [PubMed]

49. Belgio, E.; Kapitonova, E.; Chmeliov, J.; Duffy, C.D.; Ungerer, P.; Valkunas, L.; Ruban, A.V. Economic photoprotection in photosystem II that retains a complete light-harvesting system with slow energy traps. Nat. Commun. 2014, 5, 4433. [CrossRef] [PubMed]

50. Brestic, M.; Zivcak, M.; Olsovska, K.; Shao, H.B.; Kalaji, H.M.; Allakhverdiev, S.I. Reduced glutamine synthetase activity plays a role in control of photosynthetic responses to high light in barley leaves. Plant Physiol. Biochem. 2014, 81, 74-83. [CrossRef] [PubMed]

51. Kim, Y.J.; Yu, D.J.; Rho, H.; Runkle, E.S.; Lee, H.J.; Kim, K.S. Photosynthetic changes in Cymbidium orchids grown under different intensities of night interruption lighting. Sci. Hortic. 2015, 186, 124-128. [CrossRef]

52. Litthauer, S.; Battle, M.W.; Lawson, T.; Jones, M.A. Phototropins maintain robust circadian oscillation of PSII operating efficiency under blue light. Plant J. 2015, 83, 1034-1045. [CrossRef] [PubMed]

53. Pavlovič, A.; Stolárik, T.; Nosek, L.; Kouřil, R.; Ilík, P. Light-induced gradual activation of photosystem II in dark-grown Norway spruce seedlings. Biochim. Biophys. Acta 2016, 1857, 799-809. [CrossRef] [PubMed]

54. Wagner, H.; Jakob, T.; Lavaud, J.; Wilhelm, C. Photosystem II cycle activity and alternative electron transport in the diatom Phaeodactylum tricornutum under dynamic light conditions and nitrogen limitation. Photosynth. Res. 2016, 28, 151-161. [CrossRef] [PubMed]

55. Kalaji, H.M.; Jajoo, A.; Oukarroum, A.; Brestic, M.; Zivcak, M.; Samborska, I.A.; Cetner, M.D.; Łukasik, I.; Goltsev, V.; Ladle, R.J. Chlorophyll $a$ fluorescence as a tool to monitor physiological status of plants under abiotic stress conditions. Acta Physiol. Plant. 2016, 38, 102. [CrossRef] 
56. Dąbrowski, P.; Baczewska, A.H.; Pawluśkiewicz, B.; Paunov, M.; Alexantrov, V.; Goltsev, V.; Kalaji, M.H. Prompt chlorophyll $a$ fluorescence as a rapid tool for diagnostic changes in PSII structure inhibited by salt stress in Perennial ryegrass. J. Photochem. Photobiol. B 2016, 157, 22-31. [CrossRef] [PubMed]

57. Chen, Y.Y.; Wang, Y.; Shin, L.J.; Wu, J.F.; Shanmugam, V.; Tsednee, M.; Lo, J.C.; Chen, C.C.; Wu, S.H.; Yeh, K.C. Iron is involved in the maintenance of circadian period length in Arabidopsis. Plant Physiol. 2013, 161, 1409-1420. [CrossRef] [PubMed]

58. Chen, S.; Yang, J.; Zhang, M.; Strasser, R.J.; Qiang, S. Classification and characteristics of heat tolerance in Ageratina adenophora populations using fast chlorophyll a fluorescence rise OJIP. Environ. Exp. Bot. 2016, 122, 126-140. [CrossRef]

59. Sharma, D.K.; Andersen, S.B.; Ottosen, C.O.; Rosenqvist, E. Wheat cultivars selected for high Fv/Fm under heat stress maintain high photosynthesis, total chlorophyll, stomatal conductance, transpiration and dry matter. Physiol. Plant. 2015, 153, 284-298. [CrossRef] [PubMed]

60. Fan, X.; Zhang, Z.; Gao, H.; Yang, C.; Liu, M.; Li, Y.; Li, P. Photoinhibition-like damage to the photosynthetic apparatus in plant leaves induced by submergence treatment in the dark. PLoS ONE 2014, 9, e89067. [CrossRef] [PubMed]

61. Schuback, N.; Flecken, M.; Maldonado, M.T.; Tortell, P.D. Diurnal variation in the coupling of photosynthetic electron transport and carbon fixation in iron-limited phytoplankton in the NE subarctic Pacific. Biogeosciences 2016, 13, 1019-1035. [CrossRef]

62. Pan, W.J.; Wang, X.; Deng, Y.R.; Li, J.H.; Chen, W.; Chiang, J.Y.; Yang, J.B.; Zheng, L. Nondestructive and intuitive determination of circadian chlorophyll rhythms in soybean leaves using multispectral imaging. Sci. Rep. 2015, 5, 11108. [CrossRef] [PubMed]

63. Mas, P.; Yanovsky, M.J. Time for circadian rhythms: Plants get synchronized. Curr. Opin. Plant Biol. 2009, 12, 574-579. [CrossRef] [PubMed]

64. Asada, K.; Kiso, K.; Yoshikawa, K. Univalent reduction of molecular oxygen by spinach chloroplasts on illumination. J. Biol. Chem. 1974, 249, 2175-2181. [PubMed]

65. Fryer, M.J.; Ball, L.; Oxborough, K.; Karpinski, S.; Mullineaux, P.M.; Baker, N.R. Control of Ascorbate Peroxidase 2 expression by hydrogen peroxide and leaf water status during excess light stress reveals a functional organisation of Arabidopsis leaves. Plant J. 2003, 33, 691-705. [CrossRef] [PubMed]

66. Zulfugarov, I.S.; Tovuu, A.; Eu, Y.J.; Dogsom, B.; Poudyal, R.S.; Nath, K.; Hall, M.; Banerjee, M.; Yoon, U.C.; Moon, Y.H.; et al. Production of superoxide from Photosystem II in a rice (Oryza sativa L.) mutant lacking PsbS. BMC Plant Biol. 2014, 14, 242. [CrossRef] [PubMed]

67. Santa-Cruz, D.M.; Pacienza, N.A.; Zilli, C.G.; Tomaro, M.L.; Balestrasse, K.B.; Yannarelli, G.G. Nitric oxide induces specific isoforms of antioxidant enzymes in soybean leaves subjected to enhanced ultraviolet-B radiation. J. Photochem. Photobiol. B 2014, 141, 202-209. [CrossRef] [PubMed]

68. Poudyal, R.S.; Nath, K.; Zulfugarov, I.S.; Lee, C.H. Production of superoxide from photosystem II-light harvesting complex II supercomplex in STN8 kinase knock-out rice mutants under photoinhibitory illumination. J. Photochem. Photobiol. B 2016, 162, 240-247. [CrossRef] [PubMed]

69. Romero-Puertas, M.; Rodríguez-Serrano, M.; Corpas, F.; Gómez, M.; Del Rio, L.; Sandalio, L. Cadmium-induced subcellular accumulation of $\mathrm{O}_{2}{ }^{-}$and $\mathrm{H}_{2} \mathrm{O}_{2}$ in pea leaves. Plant Cell Environ. 2004, 27, 1122-1134. [CrossRef]

70. Signorelli, S.; Corpas, F.J.; Borsani, O.; Barroso, J.B.; Monza, J. Water stress induces a differential and spatially distributed nitro-oxidative stress response in roots and leaves of Lotus japonicus. Plant Sci. 2013, 201, 137-146. [CrossRef] [PubMed]

71. Thordal-Christensen, H.; Zhang, Z.; Wei, Y.; Collinge, D.B. Subcellular localization of $\mathrm{H}_{2} \mathrm{O}_{2}$ in plants. $\mathrm{H}_{2} \mathrm{O}_{2}$ accumulation in papillae and hypersensitive response during the barley-powdery mildew interaction. Plant J. 1997, 11, 1187-1194. [CrossRef]

72. Frahry, G.; Schopfer, P. NADH-stimulated, cyanide-resistant superoxide production in maize coleoptiles analyzed with a tetrazolium-based assay. Planta 2001, 212, 175-183. [CrossRef] [PubMed]

73. Murage, E.N.; Masuda, M. Response of pepper and eggplant to continuous light in relation to leaf chlorosis and activities of antioxidative enzymes. Sci. Hortic. 1997, 70, 269-279. [CrossRef]

74. Peter, E.; Rothbart, M.; Oelze, M.L.; Shalygo, N.; Dietz, K.J.; Grimm, B. Mg protoporphyrin monomethylester cyclase deficiency and effects on tetrapyrrole metabolism in different light conditions. Plant Cell Physiol. 2010, 51, 1229-1241. [CrossRef] [PubMed] 
75. Chen, S.; Yin, C.; Qiang, S.; Zhou, F.; Dai, X. Chloroplastic oxidative burst induced by tenuazonic acid, a natural photosynthesis inhibitor, triggers cell necrosis in Eupatorium adenophorum Spreng. Biochim. Biophys. Acta 2010, 1797, 391-405. [CrossRef] [PubMed]

76. Pospíšil, P. Production of reactive oxygen species by photosystem II. Biochim. Biophys. Acta 2009, 1787, 1151-1160. [CrossRef] [PubMed]

77. Circu, M.L.; Aw, T.Y. Reactive oxygen species, cellular redox systems, and apoptosis. Free Radic. Biol. Med. 2010, 48, 749-762. [CrossRef] [PubMed]

78. Kotchoni, S.O.; Gachomo, E.W. The reactive oxygen species network pathways: An essential prerequisite for perception of pathogen attack and the acquired disease resistance in plants. Bioscience 2006, 31, 389-404. [CrossRef]

79. Shapiguzov, A.; Vainonen, J.; Wrzaczek, M.; Kangasjärvi, J. ROS-talk-How the apoplast, the chloroplast, and the nucleus get the message through. Front. Plant Sci. 2012, 3, 292. [CrossRef] [PubMed]

80. Vaahtera, L.; Brosché, M.; Wrzaczek, M.; Kangasjärvi, J. Specificity in ROS signaling and transcript signatures. Antioxid. Redox Signal. 2014, 21, 1422-1441. [CrossRef] [PubMed]

81. Mittler, R. ROS are good. Trends Plant Sci. 2017, 22, 11-19. [CrossRef] [PubMed]

82. Bennie, J.; Davies, T.W.; Cruse, D.; Gaston, K.J. Ecological effects of artificial light at night on wild plants. J. Ecol. 2016, 104, 611-620. [CrossRef]

83. Raven, J.A.; Cockell, C.S. Influence on photosynthesis of starlight, moonlight, planetlight, and light pollution (reflections on photosynthetically active radiation in the universe). Astrobiology 2006, 6, 668-675. [CrossRef] [PubMed]

(C) 2018 by the authors. Licensee MDPI, Basel, Switzerland. This article is an open access article distributed under the terms and conditions of the Creative Commons Attribution (CC BY) license (http://creativecommons.org/licenses/by/4.0/). 